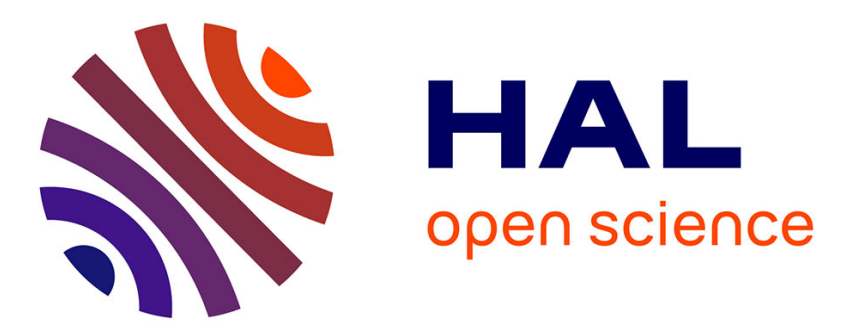

\title{
Regularized estimation of bathymetry and water quality using hyperspectral remote sensing
}

\author{
Sylvain Jay, Mireille Olwen Guillaume
}

\section{To cite this version:}

Sylvain Jay, Mireille Olwen Guillaume. Regularized estimation of bathymetry and water quality using hyperspectral remote sensing. International Journal of Remote Sensing, 2016, 37 (2), pp.263-289. 10.1080/01431161.2015.1125551 . hal-01279585

\section{HAL Id: hal-01279585 \\ https://hal.science/hal-01279585}

Submitted on 16 May 2020

HAL is a multi-disciplinary open access archive for the deposit and dissemination of scientific research documents, whether they are published or not. The documents may come from teaching and research institutions in France or abroad, or from public or private research centers.
L'archive ouverte pluridisciplinaire HAL, est destinée au dépôt et à la diffusion de documents scientifiques de niveau recherche, publiés ou non, émanant des établissements d'enseignement et de recherche français ou étrangers, des laboratoires publics ou privés. 


\title{
Regularised estimation of bathymetry and water quality using hyperspectral remote-sensing
}

\author{
S. Jay ${ }^{\mathrm{a} *}$ and M. Guillaume ${ }^{\mathrm{a}}$ \\ ${ }^{a}$ Ecole Centrale Marseille, CNRS, Aix Marseille Université, Institut Fresnel, UMR 7249, \\ 13013 Marseille, France
}

(Received 00 Month 20XX; accepted 00 Month 20XX)

\begin{abstract}
Coastal water mapping from remote-sensing hyperspectral data suffers from poor retrieval performance when the parameters to estimate do not affect much the subsurface reflectance, especially due to the ill-posed nature of the inversion problem. For example, depth cannot accurately be retrieved in deep water, when the bottom influence becomes negligible. Similarly, in very shallow water, it is difficult to estimate the water quality because the subsurface reflectance is more affected by the bottom than by optically active water components.

Most methods based on radiative tranfer model inversion actually do not consider the distributions of targeted parameters within the inversion process, thereby implicitly assuming that any parameter value in the estimation range has the same probability. In order to improve the estimation accuracy for the above limiting cases, we propose to regularise the objective functions of two estimation methods (Maximum Likelihood or ML, and Hyperspectral Optimization Process Exemplar or HOPE) by introducing local prior knowledge on the parameters of interest. To do so, loss functions are introduced into ML and HOPE objective functions in order to reduce the range of parameter estimation. These loss functions can be characterized either by using prior or expert knowledge, or by inferring this knowledge from the data (thus avoiding the use of additional information).

This approach was tested both on simulated and real hyperspectral remote sensing data. We show that the regularised objective functions are more peaked than their non-regularised counterparts when the parameter of interest does not affect much the subsurface reflectance. As a result, the estimation accuracy of regularised methods is higher for these depth ranges. In particular, when evaluated on real data, these methods were able to estimate depth up to $20 \mathrm{~m}$, while corresponding non-regularised methods were accurate up to $13 \mathrm{~m}$ on average for the same data.

This approach thus provides a solution to deal with such difficult estimation conditions. Furthermore, because no specific framework is needed, it can be extended to any estimation method that is based on iterative optimisation.
\end{abstract}

Keywords: bathymetry; hyperspectral; maximum likelihood estimation; regularisation; remote-sensing; water quality retrieval

\section{Introduction}

For the last decades, hyperspectral airborne remote-sensing has been much used for mapping of water composition and bathymetry. To do so, various models have been developed to describe the relation between the bottom reflectance and remote-sensing reflectance by taking into account water attenuation (Maritorena,

\footnotetext{
* Corresponding author. Email: sylvain.jay@fresnel.fr, +33467166459 (Sylvain Jay)
} 
Morel, and Gentili 1994; Lee et al. 1998). These models usually consider that four variable parameters affect the water-leaving radiance: depth and concentrations of optically active constituents, i.e., phytoplankton, coloured dissolved organic matter $(\mathrm{CDOM})$ and non-algal particles (NAP). Because each parameter has specific effects on spectra, it is thus possible to retrieve such water column properties from spectral shape under some conditions imposed by physical limitations. For example, depth cannot be retrieved in very optically deep water when the bottom influence becomes negligible.

Most methods can be classified into statistically- and physically-based methods (Dekker et al. 2011). On the one hand, statistical methods have been widely used for the estimation of bathymetry (Lyzenga 1978; Philpot 1989; Minghelli-Roman et al. 2007) or water constituents (O'Reilly et al. 1998; Matthews, Bernard, and Winter 2010; Ferreira et al. 2013; Loisel et al. 2014; Zhu et al. 2014; Tian et al. 2014). They aim at finding statistical relationships between spectral data (generally a few spectral bands) and the parameter of interest. On the other hand, physically-based methods lie in the use of radiative transfer models that simulate light propagation within the water body. These models can be inverted for each spectral measurement so as to retrieve model parameters such as depth or concentrations of water constituents. The inversion scheme can be performed using either look-up tables or iterative optimisation. For the look-up table approach (Louchard et al. 2003; Mobley et al. 2005; Hedley, Roelfsema, and Phinn 2009), the radiative transfer model is used in a forward mode so as to build a pre-computed data base of spectra corresponding to different combinations of depth, concentrations and bottom type. Every pixel of the image is then matched with its nearest neighbour in the data base. For iterative optimisation methods, the inversion process is performed by optimising an objective function relating modelled and measured spectra (inverse mode). The pixel-wise method developed by Lee et al. (1999) is based on least squares optimisation. Many authors have then extended this method to different applications (Klonowski, Fearns, and Lynch 2007; Brando et al. 2009; Giardino et al. 2012). Recently (Jay, Guillaume, and Blanc-Talon 2012; Jay and Guillaume 2014), we have developed a hybrid method, in which estimates of water column parameters are retrieved by maximizing the likelihood function based on a statistical sample and a radiative transfer model. This likelihood function is computed on a local neighbourhood and the estimation performance is increased by the information redundancy contained in these neighbouring pixels and the adequacy of the statistical model.

Every above mentioned method is effective over a wide range of depths. However, there are some limiting cases when the parameters to estimate do not affect much the subsurface reflectance.

First, the retrieval uncertainty generally increases when the values of the parameters to estimate (depth and/or concentrations of optically-active constituents) increase (Volpe, Silvestri, and Marani 2011; Garcia, Fearns, and McKinna 2014; Dekker et al. 2011). Indeed, high parameter values lead to a high attenuation that tends to saturate. In particular, for any water quality, there exists an intermediate depth range comprised between optically shallow water (in which the bottomrelated signal is high) and optically deep water (in which the bottom-related signal is null). In this intermediate range, the bottom influence is low so most methods lead to poor bathymetry retrieval and high uncertainty.

Second, in very shallow water, the water column is so thin that constituents do not 
affect much the subsurface reflectance (Cannizzaro and Carder 2006). Moreover, the bottom reflectance has to be perfectly known in order to retrieve such tiny effects caused by these constituents. Consequently, the accuracy of water quality retrieval is usually low in very shallow water.

In these two cases, for inversion optimisation methods, it is worth guiding the estimation process by enhancing the parameter influence on objective functions, thus reducing the uncertainty and the number of possible solutions to the inverse problem. To do so, regularisation has been used in many remote sensing applications for which the problem is ill-posed in the sense of Hadamard, e.g., for inversion of canopy radiative transfer model (Baret and Buis 2008) or unmixing of hyperspectral data (Huck, Guillaume, and Blanc-Talon 2010). For inversion of radiative transfer models, regularisation consists in introducing some constraints about the distributions of the parameters to estimate, i.e., specifying the ranges in which these parameters are more likely to vary. These ranges can be known either by using prior or expert knowledge, or by inferring this knowledge from the data (Defoin-Platel and Chami 2007).

In this paper, we propose to regularise the two objective functions respectively developed by Jay and Guillaume (2014) (referred to as Maximum Likelihood or ML) and Lee et al. (1999) (referred to as Hyperspectral Optimization Process Exemplar or HOPE by Dekker et al. (2011)). In the first case, the likelihood function is weighted by parameter probability distributions so, as a result, ML estimates are replaced by maximum a posteriori (MAP) estimates. In the second case, the $\mathrm{HOPE}$ error function is replaced by a Lagrangian function combining the original error function and loss functions.

\section{Data}

The field measurement campaign and data set construction were made by the company Actimar within the framework of the HypLitt project. This data set contains remotely sensed hyperspectral images of coastal zones with the associated ground truth (Smet, Sicot, and Lennon 2010). It also includes a library of reference spectra measured at the ground level, as well as water analyses.

\subsection{Study area}

As observed in Fig. 1, the test site was located in the Quiberon Peninsula on the French west coast (around $47^{\circ} 28^{\prime} 11^{\prime \prime} \mathrm{N}, 3^{\circ} 02^{\prime} 18^{\prime \prime} \mathrm{W}$ ) and was part of a large sandybottom area. The test site was covering an area of $0.17 \mathrm{~km}^{2}$, with depths ranging from $3 \mathrm{~m}$ to more than $20 \mathrm{~m}$ as shown on the associated bathymetric chart in Fig. 2. A shallow zone was situated in the center. High depth gradients were situated in the right part and the left part.

In Fig. 3a and Fig. 3b, we display the two hyperspectral images $\mathrm{D}_{1}$ and $\mathrm{D}_{2}$ that were acquired on Day 1 and Day 2 respectively and that were used to assess the proposed methods. Both images $\mathrm{D}_{1}$ and $\mathrm{D}_{2}$ were acquired four days apart over the same zone and at low and high tides respectively. The actual sea levels were approximately $1.50 \mathrm{~m}$ and $4.10 \mathrm{~m}$ higher for images $\mathrm{D}_{1}$ and $\mathrm{D}_{2}$ respectively compared to the bathymetric chart in Fig. 2. Lastly, a third extra image was used to show the framework of the proposed methods in Section 4.2. This image is denoted $\mathrm{D}_{2,+}$ because it was acquired a few minutes after image $\mathrm{D}_{2}$. However, the flight path of image $\mathrm{D}_{2,+}$ was perpendicular to the flight path of image $\mathrm{D}_{2}$, therefore showing 


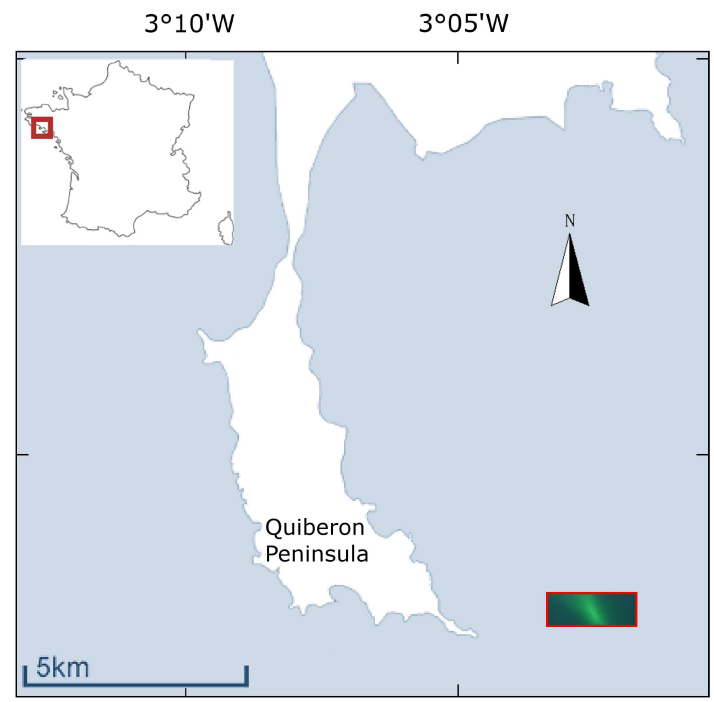

$47^{\circ} 35^{\prime} \mathrm{N}$

$47^{\circ} 30^{\prime} \mathrm{N}$

Figure 1. Location of the study area. The highlighted area at the bottom right is the test site (top left corner: $47^{\circ} 28^{\prime} 16^{\prime \prime} \mathrm{N}, 3^{\circ} 02^{\prime} 36^{\prime \prime} \mathrm{W}$; bottom right corner: $47^{\circ} 28^{\prime} 7^{\prime \prime} \mathrm{N}, 3^{\circ} 02^{\prime} 2^{\prime \prime} \mathrm{W}$ ).

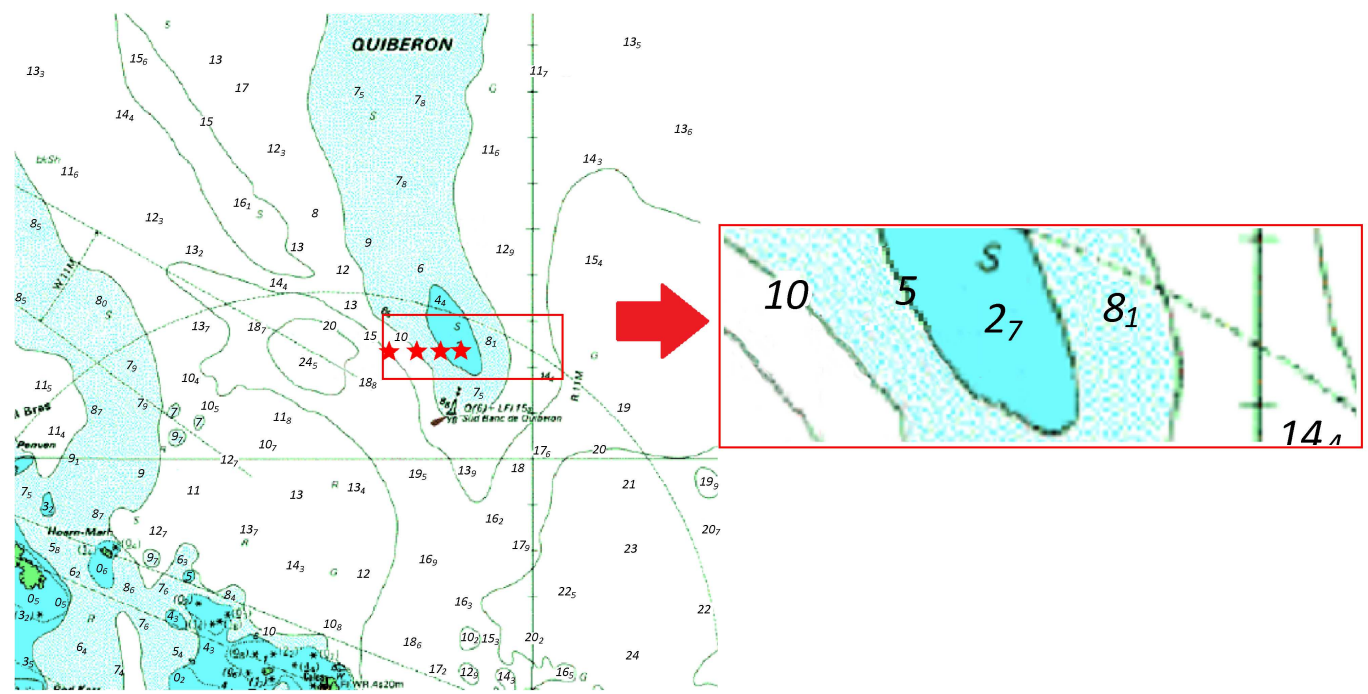

Figure 2. Bathymetric chart of the overall area (expressed in metres) with a zoom on the test site. The four red stars indicate the spots where the ground truth was measured.

other bathymetric features.

\subsection{Spectral data acquisition}

Both images $\mathrm{D}_{1}$ and $\mathrm{D}_{2}$ were acquired in September 2010 using an airborne Hyspex VNIR-1600 camera (Norsk Elektro Optikk, Norway). The weather was sunny and there were no clouds and cloud shadows. The spatial resolution was $0.5 \mathrm{~m}$ and the FWHM spectral resolution was $4.5 \mathrm{~nm}$, which corresponds to 160 spectral bands between 410 and $1000 \mathrm{~nm}$. However, the near infrared signal attenuation is so high that this wavelength range is useless for such applications, even in shallow water. As a matter of fact, only 81 spectral bands between 410 and $700 \mathrm{~nm}$ were considered. Some spectra measured along an horizontal depth gradient in both images are plotted in Fig. 3b. The associated signal-to-noise ratio (SNR) ranged from about 15:1 to 120:1 depending on considered depth (using $\mathrm{SNR}=\sigma_{\text {signal }}^{2} / \sigma_{\text {noise }}^{2}$, where $\sigma_{\text {signal }}^{2}$ and $\sigma_{\text {noise }}^{2}$ are respectively the signal and noise 
(a)

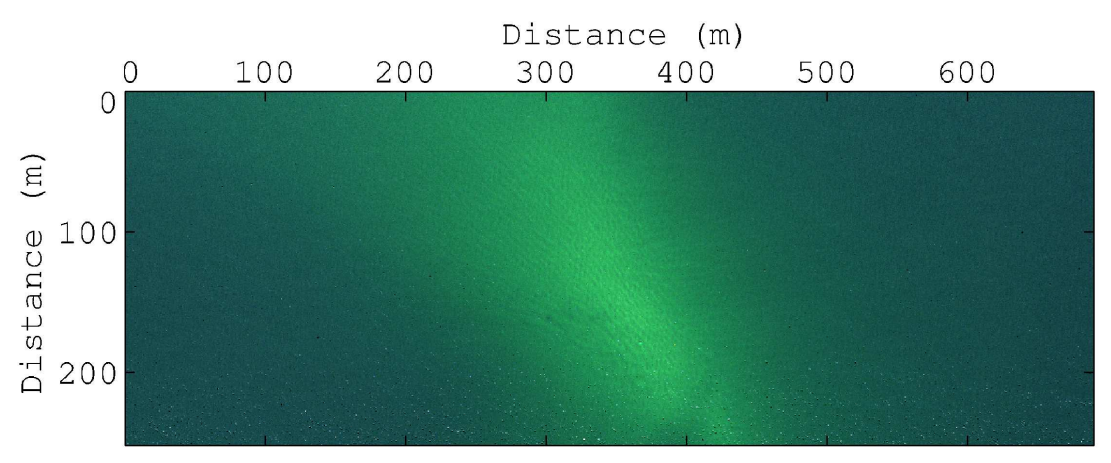

(b)

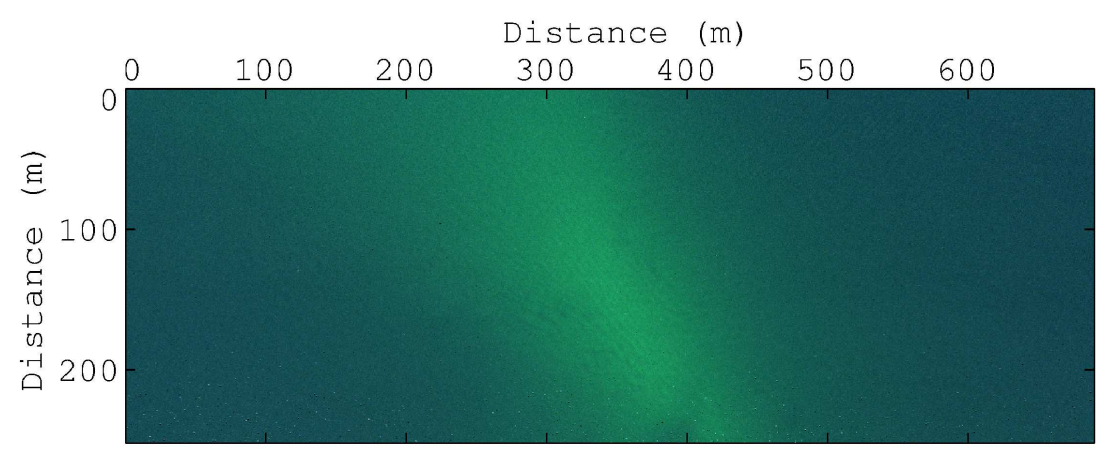

( C )

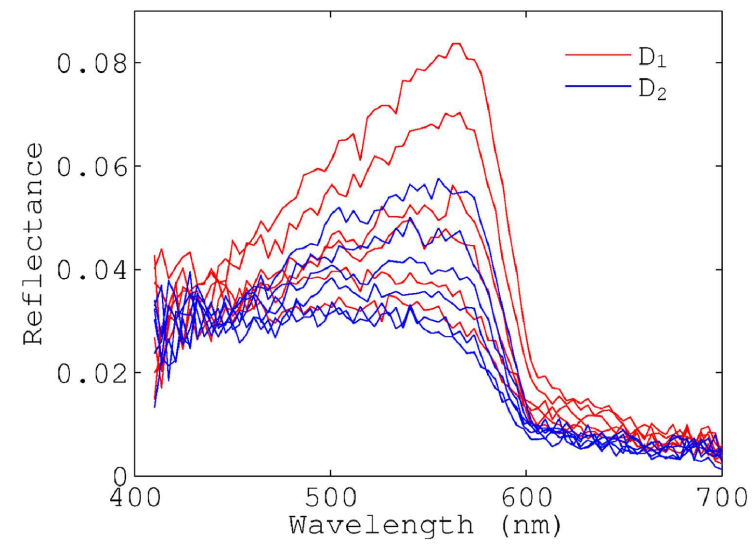

Figure 3. Remote sensing hyperspectral images used for mapping and corresponding exactly to the same test site: (a) True colour composite image $\mathrm{D}_{1}$, (b) True colour composite image $\mathrm{D}_{2}$, and (c) Reflectance spectra extracted from $\mathrm{D}_{1}$ and $\mathrm{D}_{2}$ along a horizontal transect located at a distance of $150 \mathrm{~m}$ from the origin.

sample variances computed over all the spectral bands). These spectra show that the noisiest bands were in the blue region $(410-430 \mathrm{~nm})$, where the sensitivity of the CCD camera was the lowest. The noise level was constant in remaining bands.

Some spectroradiometric measurements were also carried out beneath and over the water surface using a SVC-GER1500 spectroradiometer. They allowed the constitution of a reference spectral library that contains various ground-based materials such as sand and rocks. In particular, this reference spectral library included a sand spectrum measured over a very thin water column (few millimetres). This spectrum was used to model the bottom in the entire article. This spectral 


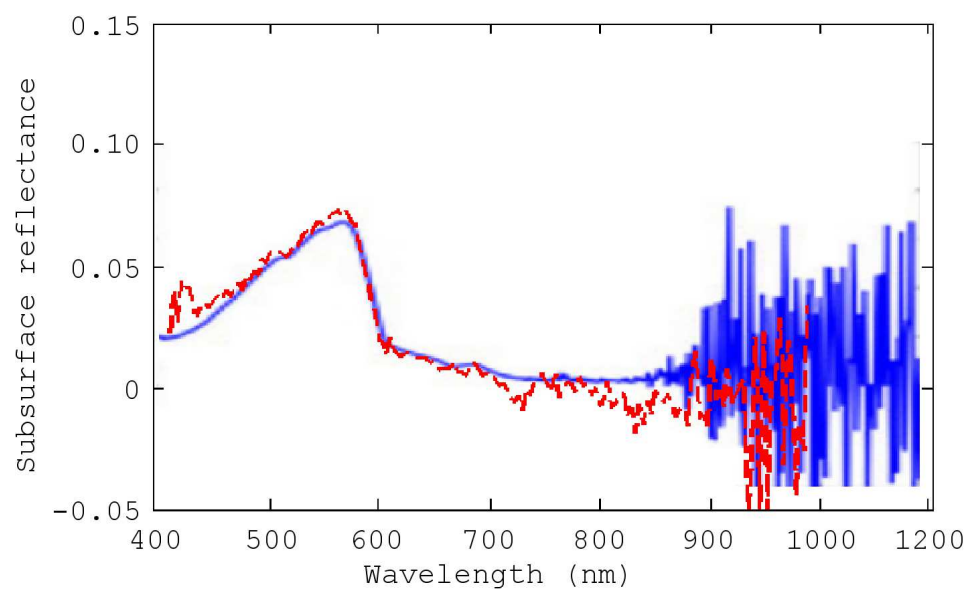

Figure 4. Example of in-situ subsurface reflectance (in blue) and retrieved subsurface reflectance (in red) in $\mathrm{D}_{1}$.

library also contained several target spectra (tarpaulins of different colours). These targets were located on the sea shore and were used to adjust the atmospheric correction. To retrieve the reflectance spectrum of each material, at least five radiance measurements were performed about one metre above the considered material. These measurements were averaged into a single radiance spectrum so as to decrease the influence of unmodelled variability (e.g., wave focusing effects for subsurface measurements). The resulting radiance spectrum was then converted into reflectance using a Spectralon white reference placed close to this material.

Several pre-processing steps were necessary before using hyperspectral images. First, data were converted into radiance, geometrically corrected, and georeferenced. The atmospheric correction was performed using the ATCOR model (Richter 2012). A set of multiplicative factors (one for each spectral band) were then derived from ground-based and ATCOR apparent reflectance spectra of reference targets (Clark et al. 2002). They were finally applied to the entire flight data set to correct from residuals from the radiative transfer algorithm and to obtain the reflectance images. The sun glint correction was performed with the method developed by Lee et al. (1999) and modified by Goodman, Lee, and Ustin (2008). Finally, we used the expression of Lee et al. (1999) (Eq. 2) to model the air-water interface. The quality of these corrections over the whole original spectral ranges is illustrated in Fig. 4: between 410 and $700 \mathrm{~nm}$, one sees that there is a close fit between the actual in-situ subsurface reflectance measured with the spectroradiometer and the remote-sensing subsurface reflectance retrieved with the above pretreatments (the noisiest parts outside the $410-700 \mathrm{~nm}$ range being removed as mentioned above).

\subsection{Reference depth and water quality measurements}

For both images $\mathrm{D}_{1}$ and $\mathrm{D}_{2}$, a sonar was used to measure depth in the four locations indicated in Fig. 2. Because of different tide heights, depth values were different for images $D_{1}$ and $D_{2}$. For image $D_{1}$, depth values were $4.70 \mathrm{~m}, 6.70 \mathrm{~m}$, $11.80 \mathrm{~m}$ and $16.80 \mathrm{~m}$, while for image $\mathrm{D}_{2}$, they were $7.30 \mathrm{~m}, 9.30 \mathrm{~m}, 14.40 \mathrm{~m}$ and $19.40 \mathrm{~m}$ (when going from the right-hand side to the left-hand side of the bathymetric chart).

For image $\mathrm{D}_{1}$, water quality was also evaluated in the same four locations by mea- 
Table 1. Concentrations measured at different depths for image $\mathrm{D}_{1}$ $\left(C_{\mathrm{PHY}}\right.$ in $\mu \mathrm{g} . \mathrm{l}^{-1}, C_{\mathrm{NAP}}$ in mg. $\left.1^{-1}\right)$.

\begin{tabular}{cccccc}
\hline & Variable & $\mathbf{4 . 7 0} \mathbf{~ m}$ & $\mathbf{6 . 7 0} \mathbf{~ m}$ & $\mathbf{1 1 . 8 0} \mathbf{~ m}$ & $\mathbf{1 6 . 8 0} \mathbf{~ m}$ \\
\hline \multirow{2}{*}{ Bottom } & $C_{\text {PHY }}$ & 1.5 & 1.5 & 1.6 & 3.0 \\
& $C_{\text {NAP }}$ & $<2.0$ & $<2.0$ & $<2.0$ & $<2.0$ \\
\hline \multirow{2}{*}{ Surface } & $C_{\text {PHY }}$ & 1.5 & 2.4 & 2.2 & 2.0 \\
& $C_{\text {NAP }}$ & 3.0 & $<2.0$ & $<2.0$ & $<2.0$ \\
\hline \multirow{2}{*}{ Mean } & $C_{\text {PHY }}$ & 1.5 & 2.0 & 1.9 & 2.5 \\
& $C_{\text {NAP }}$ & $<2.5$ & $<2.0$ & $<2.0$ & $<2.0$ \\
\hline
\end{tabular}

(a)

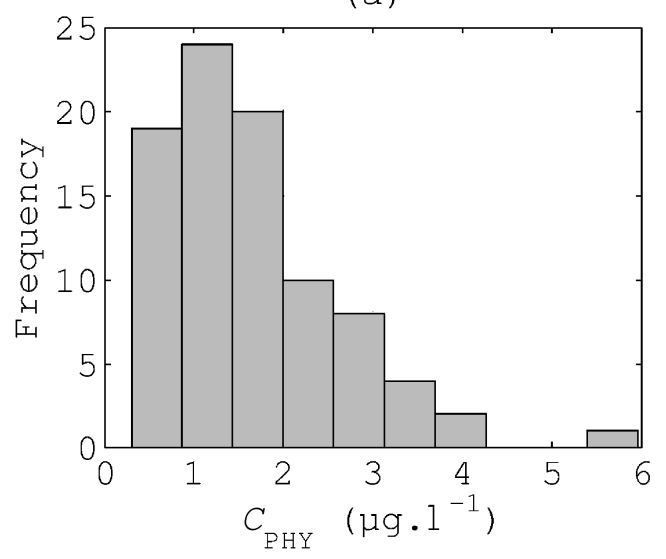

(b)

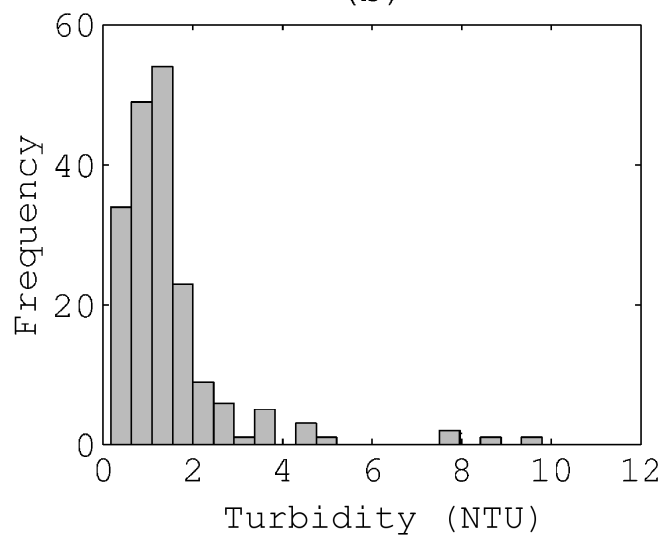

Figure 5. Histograms of Ifremer measurements: (a) $C_{\mathrm{PHY}}\left(\right.$ in $\mu \mathrm{g} . \mathrm{l}^{-1}$ ), and (b) Turbidity (in NTU, Nephelometric Turbidity Unit).

suring phytoplankton and NAP concentrations. Note that unfortunately, CDOM concentration $\left(C_{\mathrm{CDOM}}\right)$ was not measured. These measurements are presented in Table 1. Water samples were collected at surface and bottom levels, and analysed. Chlorophyll- $a$ and pheopigment were measured according to the French Standard NF T 90-117 (AFNOR December 1999). Phytoplankton concentration $\left(C_{\mathrm{PHY}}\right)$ was given by the sum of chlorophyll- $a$ and pheopigment concentrations. NAP concentration $\left(C_{\mathrm{NAP}}\right)$ was measured according to the French Standard NF EN 872 (AFNOR June 2005). For both $C_{\mathrm{PHY}}$ and $C_{\mathrm{NAP}}$, we used the means of surface and bottom measurements as reference values.

For image $\mathrm{D}_{2}$, unfortunately, no water quality measurements were available.

We also used another set built by Ifremer (2011) in order to know how concentration parameters were varying within the considered area. This database contains hundreds of phytoplankton and turbidity measurements carried out between 1996 and 2003 in the Quiberon Peninsula (note that unfortunately, no CDOM measurements were available). Turbidity is closely related to suspended matter (Doxaran et al. 2009), and therefore to both $C_{\mathrm{PHY}}$ and $C_{\mathrm{NAP}}$. For each year, we kept the data that had been collected between July and November, i.e two months before and after the date of the HypLitt campaign. The histograms of these measurements are displayed in Fig. 5. 


\section{Methods}

\subsection{Bio-optical modelling}

As previously mentioned, many authors have studied the potential of hyperspectral data to retrieve water column properties. Various models of subsurface reflectance have therefore been developed. For coastal environments, a realistic model has been presented by Lee et al. (1999) and has been widely used during the last decade (Xiu et al. 2009; Brando et al. 2009; Volpe, Silvestri, and Marani 2011; Garcia, Fearns, and McKinna 2014):

$$
r_{\bmod }(\lambda)=r_{\infty}(\lambda)\left(1-\mathrm{e}^{-\left(k_{\mathrm{d}}(\lambda)+k_{\mathrm{u}}^{\mathrm{c}}(\lambda)\right) H}\right)+\frac{R_{0, \mathrm{~B}}(\lambda)}{\pi} \mathrm{e}^{-\left(k_{\mathrm{d}}(\lambda)+k_{\mathrm{u}}^{\mathrm{b}}(\lambda)\right) H}
$$

where $\lambda$ is the wavelength, $r_{\bmod }(\lambda)$ is the modelled subsurface remote-sensing reflectance, and $r_{\infty}(\lambda)$ is the modelled subsurface remote-sensing reflectance over an optically deep water column. $R_{0, \mathrm{~B}}(\lambda)$ is the bottom albedo (the bottom is assumed to be a Lambertian reflector). $k_{\mathrm{d}}(\lambda)$ is the attenuation coefficient of downwelling photons. $k_{\mathrm{u}}^{\mathrm{b}}(\lambda)\left(\right.$ resp. $\left.k_{\mathrm{u}}^{\mathrm{c}}(\lambda)\right)$ is the attenuation coefficient of upwelling photons that interact (resp. do not interact) with the bottom. $H$ is the depth. The first term in Eq. 1 is the water column contribution (predominant in deep water) whereas the second term is the bottom contribution.

The previous equation is expressed in matrix notation as follows:

$$
r_{\text {mod }}=r_{\infty}+\mathbf{K}_{\mathrm{B}} \boldsymbol{r}_{0, \mathrm{~B}}-\mathbf{K}_{\mathrm{C}} \boldsymbol{r}_{\infty}
$$

where $\boldsymbol{r}_{\text {mod }}=\left[r_{\text {mod }}\left(\lambda_{1}\right), \ldots, r_{\text {mod }}\left(\lambda_{L}\right)\right]^{T}$ is the modelled subsurface remotesensing reflectance spectrum (superscript ' $T$, referring to transposition), $\boldsymbol{r}_{\infty}=\left[r_{\infty}\left(\lambda_{1}\right), \ldots, r_{\infty}\left(\lambda_{L}\right)\right]^{T}$ is the modelled subsurface remote-sensing reflectance spectrum over an optically deep water column, $L$ is the number of spectral bands, $r_{0, \mathrm{~B}}=\left[\frac{R_{0, \mathrm{~B}}\left(\lambda_{1}\right)}{\pi}, \ldots, \frac{R_{0, \mathrm{~B}}\left(\lambda_{L}\right)}{\pi}\right]^{T}$ is the bottom reflectance spectrum, and $\mathbf{K}_{\mathrm{B}}$ and $\mathbf{K}_{\mathrm{C}}$ are the attenuation matrices of photons that interact and respectively do not interact with the bottom. $\mathbf{K}_{B}$ and $\mathbf{K}_{C}$ are given by $\mathbf{K}_{B}=\operatorname{diag}\left[\mathrm{e}^{-\left(k_{\mathrm{d}}\left(\lambda_{l}\right)+k_{\mathrm{u}}^{\mathrm{b}}\left(\lambda_{l}\right)\right) H}\right]_{l \in \llbracket 1 ; L \rrbracket}$, and $\mathbf{K}_{\mathrm{C}}=\operatorname{diag}\left[\mathrm{e}^{-\left(k_{\mathrm{d}}\left(\lambda_{l}\right)+k_{\mathrm{u}}^{\mathrm{c}}\left(\lambda_{l}\right)\right) H}\right]_{l \in \llbracket 1 ; L \rrbracket}$.

The attenuation coefficients $k_{\mathrm{d}}(\lambda), k_{\mathrm{u}}^{\mathrm{b}}(\lambda)$, and $k_{\mathrm{u}}^{\mathrm{c}}(\lambda)$, as well as the reflectance of an infinitely deep water column $r_{\infty}(\lambda)$ have been given by Lee et al. (1999):

$$
\begin{aligned}
k_{\mathrm{d}}(\lambda) & =\frac{a(\lambda)+b_{\mathrm{b}}(\lambda)}{\cos \theta_{\mathrm{s}}} \\
k_{\mathrm{u}}^{\mathrm{b}}(\lambda) & =\frac{1}{\cos \theta_{\mathrm{v}}}\left(1.04\left(a(\lambda)+b_{\mathrm{b}}(\lambda)\right)\left(1+5.4 \frac{b_{\mathrm{b}}(\lambda)}{a(\lambda)+b_{\mathrm{b}}(\lambda)}\right)^{0.5}\right. \\
k_{\mathrm{u}}^{\mathrm{c}}(\lambda) & =\frac{1}{\cos \theta_{\mathrm{v}}}\left(1.03\left(a(\lambda)+b_{\mathrm{b}}(\lambda)\right)\left(1+2.4 \frac{b_{\mathrm{b}}(\lambda)}{a(\lambda)+b_{\mathrm{b}}(\lambda)}\right)^{0.5}\right. \\
r_{\infty}(\lambda) & =\left(0.084+0.17 \frac{b_{\mathrm{b}}(\lambda)}{a(\lambda)+b_{\mathrm{b}}(\lambda)}\right) \frac{b_{\mathrm{b}}(\lambda)}{a(\lambda)+b_{\mathrm{b}}(\lambda)}
\end{aligned}
$$

in which $\theta_{\mathrm{s}}$ and $\theta_{\mathrm{v}}$ are respectively the solar zenith angle and view angle. Absorption and backscattering coefficients $a(\lambda)$ and $b_{\mathrm{b}}(\lambda)$ mentioned in the above equations characterize physical interactions between light and water. They are mainly depen- 
dent on three optically active constituents: phytoplankton pigments, CDOM and NAP. The absorption and backscattering coefficients are usually determined by the sum of each constituent contribution. Ideally, area- and season-specific expressions of absorption and backscattering properties should be used since for example, various phytoplankton species may have different specific absorption spectra (Ahn, Bricaud, and Morel 1992). However, because such data were not available, in this article, we have used the expressions proposed by Brando et al. (2009) and slightly modified by introducing the phytoplankton absorption model of Lee (1994). This modelling has already proven to give good estimation results for this area as observed in our previous studies (Jay 2012; Jay and Guillaume 2014). In this study, the absorption and backscattering coefficients are then given by:

$$
\begin{aligned}
& a(\lambda)=a_{\mathrm{w}}(\lambda)+\left[a_{0}(\lambda)+a_{1}(\lambda) \ln \left(0.06 C_{\mathrm{PHY}}^{0.65}\right)\right] 0.06 C_{\mathrm{PHY}} 0.65 \\
& +C_{\mathrm{CDOM}} \mathrm{e}^{-S_{\mathrm{CDOM}}\left(\lambda-\lambda_{0}\right)}+C_{\mathrm{NAP}} a_{\mathrm{NAP}}^{*}\left(\lambda_{0}\right) \mathrm{e}^{-S_{\mathrm{NAP}}\left(\lambda-\lambda_{0}\right)} \\
& b_{\mathrm{b}}(\lambda)=b_{\mathrm{b}, \mathrm{w}}(\lambda)+C_{\mathrm{PHY}} b_{\mathrm{b}, \mathrm{PHY}}^{*}\left(\lambda_{1}\right)\left(\frac{\lambda_{1}}{\lambda}\right)^{Y_{\mathrm{PHY}}}+C_{\mathrm{NAP}} b_{\mathrm{b}, \mathrm{NAP}}^{*}\left(\lambda_{1}\right)\left(\frac{\lambda_{1}}{\lambda}\right)^{Y_{\mathrm{NAP}}}
\end{aligned}
$$

where reference wavelengths are fixed: $\lambda_{0}=440 \mathrm{~nm}$ and $\lambda_{1}=542 \mathrm{~nm}$.

$a_{\mathrm{w}}(\lambda)$ is the absorption spectrum of pure water and has been given by the average of three of the most frequently used spectra in the literature, namely the one of Pope and Fry (1997), the one of Smith and Baker (1981) and the one of Buiteveld, Hakvoort, and Donze (1994). The backscattering spectrum of pure water $b_{\mathrm{b}, \mathrm{w}}(\lambda)$ has been given by Morel (1974), this spectrum being used in numerous studies (Carder et al. 2004; Brando et al. 2009; Richardson and LeDrew 2006). $a_{0}(\lambda)$ and $a_{1}(\lambda)$ are the empirical coefficients provided by Lee (1994).

$b_{\mathrm{b}, \mathrm{PHY}}^{*}\left(\lambda_{1}\right), a_{\mathrm{NAP}}^{*}\left(\lambda_{0}\right), b_{\mathrm{b}, \mathrm{NAP}}^{*}\left(\lambda_{1}\right), S_{\mathrm{CDOM}}, S_{\mathrm{NAP}}, Y_{\mathrm{PHY}}$ and $Y_{\mathrm{NAP}}$ have been provided by Brando et al. (2009). $b_{\mathrm{b}, \mathrm{PHY}}^{*}\left(\lambda_{1}\right)$ is the specific backscattering coefficient of phytoplankton at the reference wavelength $\lambda_{1} \cdot a_{\mathrm{NAP}}^{*}\left(\lambda_{0}\right)$ and $b_{\mathrm{b}, \mathrm{NAP}}^{*}\left(\lambda_{1}\right)$ are respectively the specific absorption and backscattering coefficients of NAP at the reference wavelengths $\lambda_{0}$ and $\lambda_{1} . S_{\mathrm{CDOM}}$ and $S_{\mathrm{NAP}}$ are the spectral slope constants for CDOM and NAP absorption coefficients respectively. $Y_{\mathrm{PHY}}$ and $Y_{\mathrm{NAP}}$ are the power law exponents for phytoplankton and NAP backscattering coefficients respectively.

Therefore, every equation given in this section models the relationship between the subsurface reflectance $r$ and unknown parameters $H, C_{\mathrm{PHY}}, C_{\mathrm{CDOM}}$, and $C_{\mathrm{NAP}}$.

\subsection{Published estimation methods}

In this study, regularised versions of two estimation methods are developed. The first one is the ML method recently proposed by Jay and Guillaume (2014). The second one is an inversion optimisation method that is derived from the original method developed by Lee et al. (1999) and referred to as HOPE by Dekker et al. (2011). We only make slight modifications to this method, for example, in order to use it with the above mentioned bio-optical model. Both ML and HOPE are described in the following sections. 


\subsubsection{Maximum Likelihood (ML) method}

Unlike most estimation methods, this method uses both the information provided by the statistical model of reflectance variability, and the information redundancy contained in neighbouring pixels, which are often affected by the same water column if the spatial resolution is high enough. The basis has been introduced by Jay, Guillaume, and Blanc-Talon (2012). A likelihood function $P\left(\chi_{N} \mid \boldsymbol{\vartheta}\right)$ is computed from a statistical sample $\chi_{N}=\left\{\boldsymbol{r}_{1}, \ldots, \boldsymbol{r}_{N}\right\}$ of $N$ neighbouring pixels, which are assumed to be realizations of a single random vector that follows a multivariate Gaussian distribution:

$$
P\left(\chi_{N} \mid \boldsymbol{\vartheta}\right)=\prod_{i}^{N} \frac{1}{\sqrt{(2 \pi)^{L}|\boldsymbol{\Gamma}|}} \mathrm{e}^{-\frac{1}{2}\left(\boldsymbol{r}_{i}-\boldsymbol{\mu}\right)^{T} \boldsymbol{\Gamma}^{-1}\left(\boldsymbol{r}_{i}-\boldsymbol{\mu}\right)}
$$

where $\boldsymbol{\vartheta}=\left[H, C_{\mathrm{PHY}}, C_{\mathrm{CDOM}}, C_{\mathrm{NAP}}\right]^{T}$ is the vector of unknown parameters, and $\boldsymbol{\mu}=\boldsymbol{\mu}(\boldsymbol{\vartheta})$ and $\boldsymbol{\Gamma}=\boldsymbol{\Gamma}(\boldsymbol{\vartheta})$ are respectively the mean spectrum and the covariance matrix of the Gaussian distribution. In real scenarios, $\boldsymbol{\mu}(\boldsymbol{\vartheta})$ is expressed using the bio-optical model presented in Section 3.1:

$$
\boldsymbol{\mu}(\boldsymbol{\vartheta})=\boldsymbol{r}_{\infty}(\boldsymbol{\vartheta})+\mathbf{K}_{\mathrm{B}}(\boldsymbol{\vartheta}) \boldsymbol{\mu}_{0, \mathrm{~B}}-\mathbf{K}_{\mathrm{C}}(\boldsymbol{\vartheta}) \boldsymbol{r}_{\infty}(\boldsymbol{\vartheta})
$$

where $\boldsymbol{\mu}_{0, \mathrm{~B}}$ is the mean bottom spectrum which is assumed to be constant in the statistical sample $\chi_{N} . \boldsymbol{\Gamma}(\boldsymbol{\vartheta})$ is replaced by its ML estimate computed from the data $\chi_{N}$ as follows:

$$
\widehat{\boldsymbol{\Gamma}}_{\mathrm{ML}}\left(\chi_{N} ; \boldsymbol{\vartheta}\right)=\frac{1}{N} \sum_{i=1}^{N}\left(\boldsymbol{r}_{i}-\boldsymbol{\mu}(\boldsymbol{\vartheta})\right)\left(\boldsymbol{r}_{i}-\boldsymbol{\mu}(\boldsymbol{\vartheta})\right)^{T}
$$

Note that the size of the sample $\chi_{N}$ has been already discussed for a specific covariance model in a previous paper (Jay and Guillaume 2011).

The ML estimate $\widehat{\vartheta}_{\mathrm{ML}}\left(\chi_{N}\right)$ is the value of $\boldsymbol{\vartheta}$ that maximizes the likelihood function as follows:

$$
\widehat{\boldsymbol{\vartheta}}_{\mathrm{ML}}\left(\chi_{N}\right)=\underset{\boldsymbol{\vartheta}}{\operatorname{argmax}} P\left(\chi_{N} \mid \boldsymbol{\vartheta}\right) .
$$

Recently (Jay and Guillaume 2014), we have used this method to develop a multiresolution ML mapping method, in which the bathymetry resolution depends on local depth. The entire image is first divided using appropriate meshes and $\boldsymbol{\vartheta}$ is then estimated in every mesh. On the one hand, in shallow water, the SNR is high so local depth variations can be finely retrieved by introducing a linear depth model into the likelihood expression, i.e., by replacing the single $H$ value estimated in the considered mesh by $H_{i j}=A \times i+B \times j+H_{0}$, where $(i, j)$ refers to the mesh pixel $(i, j)$ and $A, B$ and $H_{0}$ are extra parameters describing the linear depth model. On the other hand, in deep water, the SNR is lower so estimating the local mean depth in the considered mesh using the original constant depth model is more robust and accurate. Final maps are obtained by combining these estimated maps according to local depth.

Note that initialization is not a major problem for ML. Indeed, for a spatially homogeneous water column, the likelihood function is smooth (because it is averaged on a sample of several pixels) and locally convex (Jay and Guillaume 2014). 


\subsubsection{Hyperspectral Optimization Process Exemplar (HOPE) method}

This pixel-wise method involves minimizing an error function relating the actual spectrum to the modelled spectrum. In this article, because the wavelengths range from 410 to $700 \mathrm{~nm}$ for the considered hyperspectral images, this function is restricted to the following expression:

$$
f_{\mathrm{HOPE}}(\boldsymbol{r} ; \boldsymbol{\vartheta})=\frac{\left[\sum_{\lambda_{i}=410}^{675}\left(r\left(\lambda_{i}\right)-r_{\bmod }\left(\lambda_{i} ; \boldsymbol{\vartheta}\right)\right)^{2}\right]^{0.5}}{\sum_{\lambda_{i}=410}^{675} r\left(\lambda_{i}\right)}
$$

where $r\left(\lambda_{i}\right)$ is the measured subsurface reflectance at wavelength $\lambda_{i}$, $\boldsymbol{r}=\left[r\left(\lambda_{1}\right), \ldots, r\left(\lambda_{L}\right)\right]^{T}$, and $r_{\bmod }\left(\lambda_{i} ; \boldsymbol{\vartheta}\right)$ is the modelled subsurface reflectance given by the bio-optical model presented in Section 3.1.

The HOPE estimate $\widehat{\boldsymbol{\vartheta}}_{\text {HOPE }}(\boldsymbol{r})$ is the value of $\boldsymbol{\vartheta}$ that minimizes the above error function as follows:

$$
\widehat{\boldsymbol{\vartheta}}_{\mathrm{HOPE}}(\boldsymbol{r})=\underset{\boldsymbol{\vartheta}}{\operatorname{argmin}} f_{\mathrm{HOPE}}(\boldsymbol{r} ; \boldsymbol{\vartheta}) .
$$

Compared to ML that takes into account spatial and spectral correlations, HOPE works on a pixel-by-pixel basis and does not use correlation between bands.

In the original HOPE (Lee et al. 1999), the bottom reflectance value at $550 \mathrm{~nm}$ is also estimated. However, because the objective of this study is to tackle the limitations of this estimation method in very shallow water and in deep water, it is worth limiting the number of unknowns and assuming that the bottom is known. Choosing an appropriate initialization is more important for HOPE than for ML because the latter uses more spatial and spectral information, thus reducing the estimation uncertainty and the number of possible solutions to the inverse problem. Indeed, various sets of input parameters can lead to roughly the same reflectance spectrum (Sydor et al. 2004; Defoin-Platel and Chami 2007). In this paper, for each pixel, initial values of $H, C_{\mathrm{PHY}}, C_{\mathrm{CDOM}}$ and $C_{\mathrm{NAP}}$ are derived from those proposed by Dekker et al. (2011):

$$
\begin{aligned}
C_{\mathrm{PHY}, \text { init }} & =\left[\frac{5}{6}\left(\frac{r(440)}{r(550)}\right)^{-1.7}\right]^{\frac{1}{0.65}} \\
C_{\mathrm{CDOM}, \text { init }} & =0.075\left(\frac{r(440)}{r(550)}\right)^{-1.7} \\
C_{\mathrm{NAP}, \text { init }} & =\frac{8}{b_{\mathrm{b}, \mathrm{NAP}}^{*}\left(\lambda_{1}\right)} r(660) \\
H_{\text {init }} & =\frac{1}{0.3}\left(\frac{r(440)}{r(550)}\right)^{1.7}
\end{aligned}
$$

where $r(440), r(550)$ and $r(660)$ are the measured reflectance values at wavelengths 440, 550 and $660 \mathrm{~nm}$. As recommended by Dekker et al. (2011), before inversion, every spectrum is smoothed for wavelengths ranging from 600 to $675 \mathrm{~nm}$. For this purpose, we use the Savitsky-Golay algorithm (Savitsky and Golay 1964) with a window width of nine bands and a second degree polynomial. 


\subsection{Regularisation of estimation methods}

\subsubsection{Maximum A Posteriori (MAP) method}

In Bayesian statistical inference, using parameter prior probability distributions to obtain the Maximum A Posteriori (MAP) estimator can be regarded as regularising the likelihood function of Eq. 9. These prior distributions describe how and within which range the parameters vary. Using this information thus prevents from obtaining aberrant values when the estimation performance decreases and the uncertainty increases (i.e., mainly for $H$ in deep water, and for $C_{\mathrm{PHY}}, C_{\mathrm{CDOM}}$, and $C_{\mathrm{NAP}}$ in shallow water).

According to the Bayes' theorem, the ML estimate $\widehat{\boldsymbol{\vartheta}}_{\mathrm{ML}}\left(\chi_{N}\right)$ is transformed into the MAP estimate $\widehat{\vartheta}_{\text {MAP }}\left(\chi_{N}\right)$, which is the value of $\boldsymbol{\vartheta}$ that maximizes the posterior distribution $P\left(\boldsymbol{\vartheta} \mid \chi_{N}\right)$ :

$$
\begin{aligned}
& \widehat{\boldsymbol{\vartheta}}_{\mathrm{MAP}}\left(\chi_{N}\right)=\underset{\boldsymbol{\vartheta}}{\operatorname{argmax}} P\left(\boldsymbol{\vartheta} \mid \chi_{N}\right)=\underset{\boldsymbol{\vartheta}}{\operatorname{argmax}} \frac{P\left(\chi_{N} \mid \boldsymbol{\vartheta}\right) \times P(\boldsymbol{\vartheta})}{P\left(\chi_{N}\right)} \\
& \widehat{\boldsymbol{\vartheta}}_{\mathrm{MAP}}\left(\chi_{N}\right)=\underset{\boldsymbol{\vartheta}}{\operatorname{argmax}} P\left(\chi_{N} \mid \boldsymbol{\vartheta}\right) \times P(\boldsymbol{\vartheta})
\end{aligned}
$$

that equals $\widehat{\boldsymbol{\vartheta}}_{\mathrm{ML}}\left(\chi_{N}\right)$ if the prior distribution $P(\boldsymbol{\vartheta})$ is uniform within the estimation range (i.e., if no information on parameter distribution is available).

In this article, we assume that every element of $\boldsymbol{\vartheta}$ is independent of each other. This is especially acceptable for coastal water where concentrations of optically active substances do not correlate (see for example Kutser (2004)). Therefore, the prior distribution can be decomposed as follows:

$$
\begin{aligned}
P(\boldsymbol{\vartheta}) & =P\left(H, C_{\mathrm{PHY}}, C_{\mathrm{CDOM}}, C_{\mathrm{NAP}}\right) \\
& =P(H) \times P\left(C_{\mathrm{PHY}}\right) \times P\left(C_{\mathrm{CDOM}}\right) \times P\left(C_{\mathrm{NAP}}\right) .
\end{aligned}
$$

Combining Eq. 20 and Eq. 22 and taking the logarithm lead to the following equation:

$$
\begin{aligned}
\widehat{\boldsymbol{\vartheta}}_{\mathrm{MAP}}\left(\chi_{N}\right)=\underset{\boldsymbol{\vartheta}}{\operatorname{argmax}}\{ & \ln \left[P\left(\chi_{N} \mid \boldsymbol{\vartheta}\right)\right]+\ln [P(H)]+\ln \left[P\left(C_{\mathrm{PHY}}\right)\right] \\
& \left.+\ln \left[P\left(C_{\mathrm{CDOM}}\right)\right]+\ln \left[P\left(C_{\mathrm{NAP}}\right)\right]\right\} .
\end{aligned}
$$

Inserting prior knowledge on parameter distributions thus amounts to adding some regularisation terms to the original log-likelihood function.

\subsubsection{REGularised Hyperspectral Optimization Process Exemplar (REG-HOPE) method}

In mathematical optimisation, regularising an objective function can be done using the method of Lagrange multipliers. The latter consists in adding a loss function $f_{i}$ for every parameter of interest. Unlike for Eq. 23 in which every term corresponds to a probability distribution and thus varies within the same range, these loss functions have to be weighted using the Lagrange multipliers $w_{i}$.

The REG-HOPE estimate $\widehat{\vartheta}_{\text {REG-HOPE }}\left(\chi_{N}\right)$ is therefore given using a Lagrangian 
derived from Eq. 13 as follows:

$$
\begin{aligned}
\widehat{\boldsymbol{\vartheta}}_{\mathrm{REG}-\mathrm{HOPE}}(\boldsymbol{r})=\underset{\boldsymbol{\vartheta}}{\operatorname{argmax}}\{ & f_{\mathrm{HOPE}}(\boldsymbol{r} ; \boldsymbol{\vartheta})+w_{1} f_{1}(H)+w_{2} f_{2}\left(C_{\mathrm{PHY}}\right) \\
& \left.+w_{3} f_{3}\left(C_{\mathrm{CDOM}}\right)+w_{4} f_{4}\left(C_{\mathrm{NAP}}\right)\right\}
\end{aligned}
$$

where $f_{\mathrm{HOPE}}(\boldsymbol{r} ; \boldsymbol{\vartheta})$ is the original function of Eq. 13 and $\left(w_{i}\right)_{i=1 \ldots 4}$ are positive scalars.

\subsubsection{Implementation on a local scale}

Appropriate loss functions for $H, C_{\mathrm{PHY}}, C_{\mathrm{CDOM}}$ and $C_{\mathrm{NAP}}$ have to be chosen for both regularised methods. Importantly, note that every regularisation scheme (one for each parameter) is independent from one another. Depending on data availability, HOPE and ML can thus only be regularised with respect to part of the parameters. From a probabilistic point of view, it amounts to considering that, for MAP, remaining non-regularised parameters follow uniform distributions within the estimation range (as implicitly assumed for ML).

In the following, one differentiates deep water from shallow water by regularising either with respect to depth or concentrations respectively.

Concerning $H$, as mentioned in introduction, there is an intermediate depth range in which the bottom influence on subsurface reflectance is very low but still exists. In this case, the uncertainty of depth estimation is higher because of the low reflectance sensitivity to an increase in depth (i.e., the so-called saturation effect also observed for vegetation remote-sensing (Baret and Buis 2008)). Hereafter, the idea is then to narrow the range in which $H$ can vary by making the highest values less probable.

In order to regularise the log-likelihood function, we use a Gaussian distribution with mean $m_{1}$ and standard deviation $\sigma_{1}$ so as to limit depth variations. The following objective function derived from Eq. 23 (in which $P\left(C_{\mathrm{PHY}}\right), P\left(C_{\mathrm{CDOM}}\right)$ and $P\left(C_{\mathrm{NAP}}\right)$ are assumed to be uniform $)$ is used to give the MAP estimate in deep water:

$$
\widehat{\boldsymbol{\vartheta}}_{\mathrm{MAP}}\left(\chi_{N}\right)=\underset{\boldsymbol{\vartheta}}{\operatorname{argmax}}\left\{\ln \left[P\left(\chi_{N} \mid \boldsymbol{\vartheta}\right)\right]-\frac{1}{2} \ln \left(2 \pi \sigma_{1}^{2}\right)-\frac{1}{2 \sigma_{1}^{2}}\left(H-m_{1}\right)^{2}\right\} .
$$

Similarly, we use a quadratic loss function in order to regularise the HOPE error function with respect to $H$ :

$$
\widehat{\boldsymbol{\vartheta}}_{\mathrm{REG}-\mathrm{HOPE}}(\boldsymbol{r})=\underset{\boldsymbol{\vartheta}}{\operatorname{argmax}}\left\{f_{\mathrm{HOPE}}(\boldsymbol{r} ; \boldsymbol{\vartheta})+w_{1} \frac{1}{2 \sigma_{1}^{2}}\left(H-m_{1}\right)^{2}\right\}
$$

Regularisation can also be performed with respect to concentration parameters, especially for very shallow water. Importantly, the concentration distributions are likely to be area-specific so they should be estimated for each study site. For the Quiberon Peninsula, we found that Gamma distributions were fitting the $C_{\mathrm{PHY}}$ and turbidity distributions presented in Fig. 5 better than normal distributions (significant with $p<0.001)$. If we assume that $P\left(C_{\mathrm{PHY}}\right), P\left(C_{\mathrm{CDOM}}\right)$ and $P\left(C_{\mathrm{NAP}}\right)$ are Gamma, the MAP estimate when applied to the Quiberon Peninsula is given using the following objective function derived from Eq. 23 (in which $P(H)$ is assumed to 
be uniform):

$$
\begin{aligned}
\widehat{\boldsymbol{\vartheta}}_{\mathrm{MAP}}\left(\chi_{N}\right)= & \underset{\boldsymbol{\vartheta}}{\operatorname{argmax}}\left\{\ln \left[P\left(\chi_{N} \mid \boldsymbol{\vartheta}\right)\right]\right. \\
& +\ln \left(C_{\mathrm{PHY}}{ }^{\left(\alpha_{2}-1\right)}\right)-\ln \left(\beta_{2}{ }^{\alpha_{2}}\right)-\ln \left[\gamma\left(\alpha_{2}\right)\right]-\frac{C_{\mathrm{PHY}}}{\beta_{2}} \\
& +\ln \left(C_{\mathrm{CDOM}}{ }^{\left(\alpha_{3}-1\right)}\right)-\ln \left(\beta_{3}{ }^{\alpha_{3}}\right)-\ln \left[\gamma\left(\alpha_{3}\right)\right]-\frac{C_{\mathrm{CDOM}}}{\beta_{3}} \\
& \left.+\ln \left(C_{\mathrm{NAP}}{ }^{\left(\alpha_{4}-1\right)}\right)-\ln \left(\beta_{4}{ }^{\alpha_{4}}\right)-\ln \left[\gamma\left(\alpha_{4}\right)\right]-\frac{C_{\mathrm{NAP}}}{\beta_{4}}\right\}
\end{aligned}
$$

where $\gamma$ is the Gamma function, and $\alpha_{i}$ and $\beta_{i}$ are respectively the shape and scale parameters of the Gamma distribution of parameter $i . \alpha_{i}$ and $\beta_{i}$ can be related to the mean $m_{i}$ and standard deviation $\sigma_{i}$ of the Gamma distribution using the method of moments (i.e., $m_{i}=\alpha_{i} \beta_{i}$ and $\sigma_{i}^{2}=\alpha_{i} \beta_{i}^{2}$ ). Note that, for example, if only in situ $C_{\mathrm{PHY}}$ measurements are available, the regularised objective function to optimise is only made of the first two rows in Eq. 27.

On the other hand, quadratic loss functions can still be used to regularise the HOPE error function with respect to concentrations (similarly to Eq. 26).

\subsubsection{Implementation for large-scale mapping}

For both methods and each parameter, regularised and non-regularised maps have to be combined to obtain a single map covering the whole depth range. Therefore, depending on local depth, estimated parameters in a given pixel are given by one of the following methods:

- In shallow water, no regularisation is performed so the original mapping method (ML or HOPE) is used. For ML, depth is modelled with a linear depth model within each statistical sample (Jay and Guillaume 2014).

- In very shallow water, if some prior knowledge of concentration distributions is available, MAP or REG-HOPE is implemented by using these data to regularise the corresponding objective function.

- In deep water, MAP or REG-HOPE is implemented by regularising the objective function with respect to depth. For MAP, depth is modelled with a constant depth model within each statistical sample (Jay and Guillaume 2014).

In real scenarios, the three above depth ranges vary according to the considered water turbidity and bottom type, and can be identified by observing the estimation uncertainty on non-regularised depth and concentration maps. For a given parameter, regularised and non-regularised maps are computed and combined according to local depth. For example, in order to combine the ML bathymetric map $\widehat{H}_{\mathrm{ML}}$ obtained for shallow water and the MAP bathymetric map $\widehat{H}_{\mathrm{MAP}}$ obtained for deep water, the following equation is used:

$$
\widehat{H}=\frac{\alpha \widehat{H}_{\mathrm{MAP}}+(2-\alpha) \widehat{H}_{\mathrm{ML}}}{2}
$$


with

$$
\alpha=\alpha(H)=\left\{\begin{array}{clc}
0 & \text { if } \quad H \leq H_{\mathrm{INF}} \\
\frac{2\left(H-H_{\mathrm{INF}}\right)}{H_{\mathrm{SUP}}-H_{\mathrm{INF}}} & \text { if } H_{\mathrm{INF}}<H<H_{\mathrm{SUP}} \\
2 & \text { if } \quad H \geq H_{\mathrm{SUP}} .
\end{array}\right.
$$

in which the depth values $H_{\mathrm{INF}}$ and $H_{\mathrm{SUP}}$ split the whole depth range into three parts so as to combine ML and MAP maps in a continuous way. Therefore, in shallow water $\left(H \leq H_{\mathrm{INF}}\right), \widehat{H}$ is given by the $\mathrm{ML}$ estimate $\widehat{H}_{\mathrm{ML}}$ (using the linear depth model). Between $H_{\mathrm{INF}}$ and $H_{\mathrm{SUP}}, \widehat{H}$ is given by a linear combination of $\widehat{H}_{\mathrm{ML}}$ and $\widehat{H}_{\mathrm{MAP}}$. In deep water $\left(H \geq H_{\mathrm{SUP}}\right), \widehat{H}$ is given by the MAP estimate $\widehat{H}_{\text {MAP }}$ (using the constant depth model).

In the following, note that MAP indistinctly refers to both the local estimation method (described in Section 3.3.3) and the overall mapping method (described in this section).

The hyperparameters $m_{i}, \sigma_{i}, \alpha_{i}$ and $\beta_{i}$ can be set differently for each depth range. In very shallow water, for every concentration $C_{i}$, the hyperparameters $\alpha_{i}$ and $\beta_{i}$ can be tuned using the assessment of an experienced expert or extra knowledge (such as the database built by Ifremer (2011) and presented in Section 2.3).

In deep water, $m_{1}$ and $\sigma_{1}$ can be inferred from the non-regularised depth map, especially from the maximum depth beyond which the estimation performance becomes poor. They can approximately be set in such a way that depths higher than this maximum depth are more penalized.

Ideally, for REG-HOPE, Lagrange multipliers (and parameters to estimate) should optimally be found by setting the partial derivatives of objective function (e.g., Eq. 26) to zero. Unfortunately, such equations are non-linear and cannot be solved easily. In this article, we propose to experimentally set Lagrange multipliers $w_{i}$ by using local prior knowledge. To do so, we assume that they are constant within the whole image and that depth and/or concentrations are known in a small area. Then, these weights are numerically estimated in this area and finally, these approximate values are re-introduced into the regularised objective function so as to estimate depth and/or concentrations in the whole image.

Conversely, MAP is easier to implement than REG-HOPE: indeed, as every term in Eq. 23 is implicitly weighted by a factor equal to one, only the hyperparameters $m_{i}, \sigma_{i}, \alpha_{i}$ and $\beta_{i}$ have to be set beforehand. Therefore, for deep water, MAP does not require any prior knowledge for retrieving depth and water quality, which is a major advantage over REG-HOPE.

\subsection{Method performance assessment}

Simulated and real data were used to test our methods. Simulated data were generated from the sand spectrum introduced in Section 2.2. The bottom variability was modelled with a white Gaussian noise $(\sigma=0.01)$. After water attenuation performed by Eq. 2, the same white Gaussian noise was added to model other sources of variability, including sensor noise. The concentration values were similar to those measured within the HypLitt data set introduced in Section 2, i.e., $C_{\mathrm{PHY}}=1.7 \mu \mathrm{g} . \mathrm{l}^{-1}, C_{\mathrm{CDOM}}=0.02 \mathrm{~m}^{-1}$, and $C_{\mathrm{NAP}}=1.5 \mathrm{mg} . \mathrm{l}^{-1}$.

The Root Mean Square Error (RMSE) was used to compare the results. The RMSE 
obtained for the estimation of parameter $X$ is defined as follows:

$$
\mathrm{RMSE}=\sqrt{\frac{1}{P} \sum_{i=1}^{P}\left(\widehat{X}_{i}-X_{i}\right)^{2}}
$$

where $P$ is the number of samples, and $X_{i}$ and $\widehat{X}_{i}$ are respectively the actual and estimated values of $X$ for sample $i$.

\section{Results and discussion}

Both simulated and real data were used to show the regularisation contribution for improving estimation performance.

\subsection{On the interest of regularisation}

Before showing the interest of regularising the ML and HOPE objective functions, in Fig. 6, we illustrate how depth and concentrations affect the subsurface reflectance model of Eq. 2 by studying the derivatives $\frac{\partial r_{\text {mod }}}{\partial H}$ and $\frac{\partial r_{\text {mod }}}{\partial C_{\text {PHY }}}$. Note that in the following, we only focus on $H$ and $C_{\mathrm{PHY}}$, but the same conclusions can be drawn with other concentrations. The $L_{2}$ norm $\left\|\frac{\partial r_{\text {mod }}}{\partial H}\right\|_{2}$ (resp. $\left.\left\|\frac{\partial r_{\text {mod }}}{\partial C_{\mathrm{PHY}}}\right\|_{2}\right)$ is plotted as a function of $H$ and $C_{\mathrm{PHY}}$ in Fig. 6a (resp. in Fig. 6b). In both cases, the lower the derivative, the lower the influence of these parameters on the model and therefore, the lower the estimation accuracy. These two figures show the inner reflectance variability only induced by the model parameters $H$ and $C_{\mathrm{PHY}}$, so other phenomena affecting estimation results, such as bottom variability, sensor noise or estimation method, are not taken into account. However, it is worth noting that any change in bottom variability (darker or brighter sand substrate, other bottom types) or sensor noise level does not affect the shape of the functions plotted in Fig. 6 (actually, such a change only modifies the overall function values).

Fig. 6a shows that $\left\|\frac{\partial r_{m o d}}{\partial H}\right\|_{2}$ is very sensitive to $H$ in shallow water, which confirms that bathymetry can be accurately retrieved in this depth range. On the other hand, the deeper the water, the lower the derivative. In this case, the subsurface reflectance model is not much affected by variation in $H$, which proves that depth cannot be estimated accurately since the bottom is barely visible. Note that, relatively to $H, C_{\mathrm{PHY}}$ does not affect much $\left\|\frac{\partial r_{\text {mod }}}{\partial H}\right\|_{2}$ in shallow water, which shows that in this depth range, the $H$ influence is so strong that depth estimation accuracy only slightly depends on water turbidity. As expected, in deeper water, the model sensitivity to variation in $H$ is higher for clearer water (low $C_{\mathrm{PHY}}$ values) for which the bottom is more visible.

The same overall behaviour is observed between $\left\|\frac{\partial r_{\text {mod }}}{\partial C_{\mathrm{PHY}}}\right\|_{2}$ and $C_{\mathrm{PHY}}$, and between $\left\|\frac{\partial r_{\text {mod }}}{\partial H}\right\|_{2}$ and $H$. Indeed, Fig. $6 \mathrm{~b}$ shows that $\left\|\frac{\partial r_{\text {mod }}}{\partial C_{\mathrm{PHY}}}\right\|_{2}$ is high for low $C_{\mathrm{PHY}}$ values and decreases when $C_{\mathrm{PHY}}$ increases. This indicates that $C_{\mathrm{PHY}}$ is better estimated for low $C_{\mathrm{PHY}}$ values.

However, there are two noticeable differences between the two figures. First, it is worth noting that $\left\|\frac{\partial r_{\text {mod }}}{\partial H}\right\|_{2}$ varies much more than $\left\|\frac{\partial r_{\text {mod }}}{\partial C_{\mathrm{PHY}}}\right\|_{2}$ in the considered ranges of depth and concentration (between 0 and 1.45 for $\left\|\frac{\partial r_{\text {mod }}}{\partial H}\right\|_{2}$, and between 0 and 0.25 for $\left.\left\|\frac{\partial r_{\bmod }}{\partial C_{\mathrm{PHY}}}\right\|_{2}\right)$. Again, this shows that $H$ has a greater influence on 


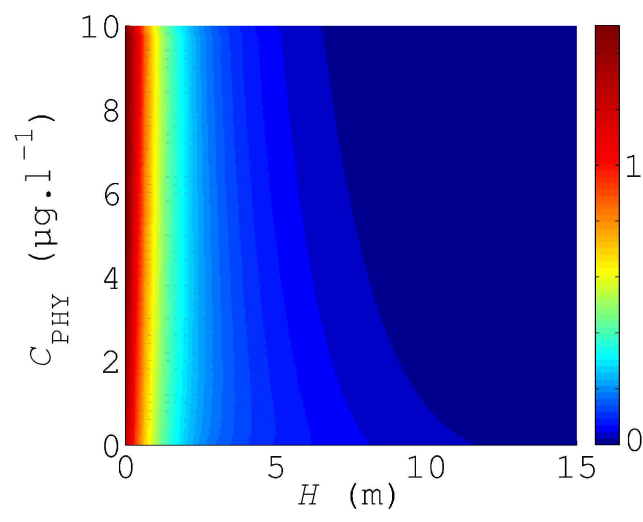

(a)

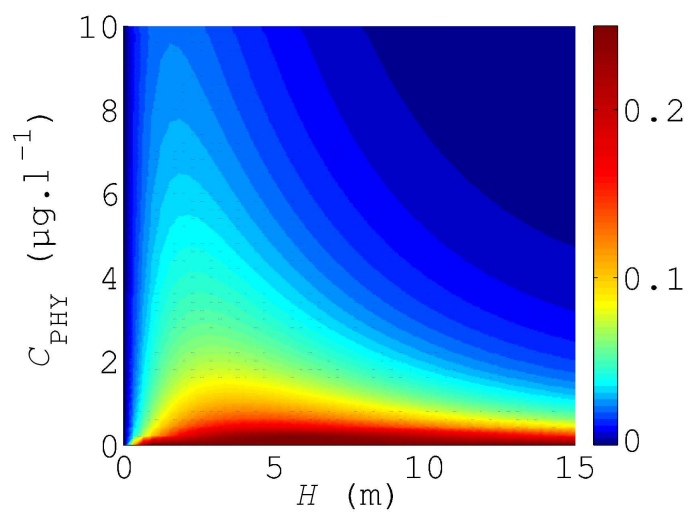

(b)

Figure 6. Norm of the derivatives of model reflectance $r_{\bmod }$ as a function of $H$ and $C_{\mathrm{PHY}}$ $\left(C_{\mathrm{CDOM}}=0.02 \mathrm{~m}^{-1} ; C_{\mathrm{NAP}}=1.5 \mathrm{mg} \cdot \mathrm{l}^{-1}\right)$. (a) Derivative with respect to $H$; (b) derivative with respect to $C_{\mathrm{PHY}}$.

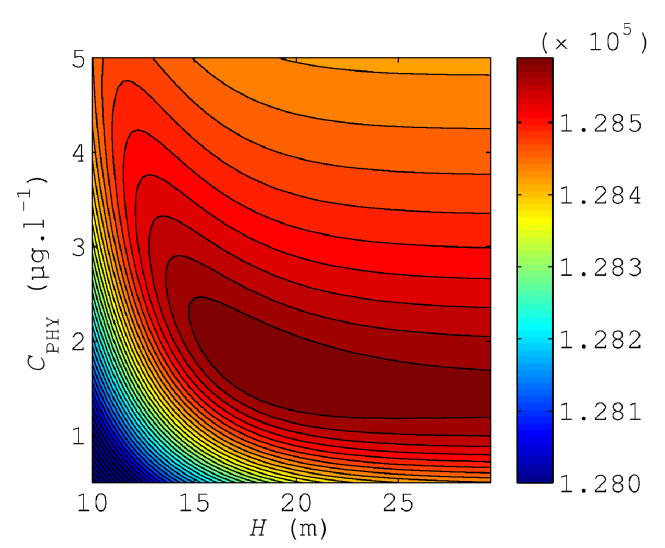

(a)

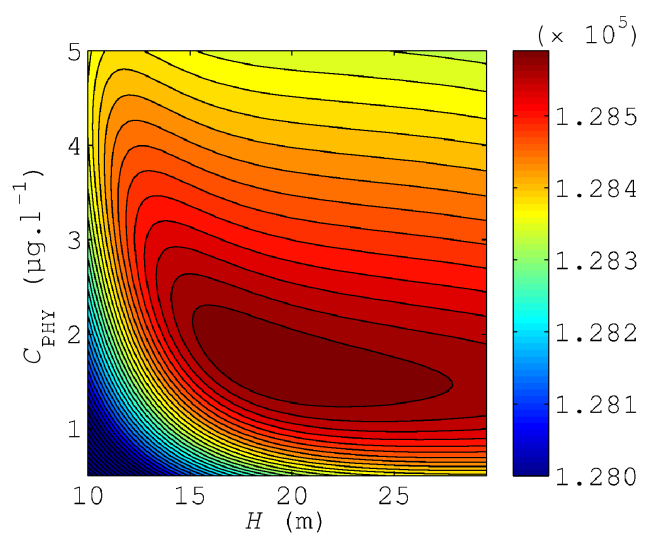

(b)

Figure 7. Log-likelihood function (a) without regularisation and (b) with regularisation with respect to $H$ and $C_{\mathrm{PHY}}$. The actual $H$ and $C_{\mathrm{PHY}}$ values are $20 \mathrm{~m}$ and $1.7 \mu \mathrm{g} \cdot \mathrm{l}^{-1}$ respectively. We set $m_{1}=20 \mathrm{~m}$, $\sigma_{1}=10 \% \times m_{1}, m_{2}=1.7 \mu \mathrm{g} \cdot 1^{-1}, \sigma_{2}=10 \% \times m_{2}$. The colour scale is the same for both figures.

subsurface reflectance than $C_{\mathrm{PHY}}$, thus indicating that it can be better estimated than $C_{\mathrm{PHY}}$.

Second, unlike for $\left\|\frac{\partial r_{\text {mod }}}{\partial H}\right\|_{2}$ and $C_{\mathrm{PHY}}$, Fig. 6b exhibits a strong relationship between $\left\|\frac{\partial r_{\bmod }}{\partial C_{\mathrm{PHY}}}\right\|_{2}$ and $H$. For depths higher than a few metres, the $C_{\mathrm{PHY}}$ estimation accuracy decreases as depth increases (thus lowering the SNR). Moreover, $C_{\mathrm{PHY}}$ cannot be accurately retrieved in very shallow water, even for low $C_{\mathrm{PHY}}$ values. In such a case, the water column is so thin that the constituents do not affect much the subsurface reflectance model, which is mainly dominated by the bottom reflectance.

Therefore, these figures indicate that the estimation accuracy could be improved at both ends of the depth range. Regularising the objective functions of Eq. 9 or Eq. 13 is a way to lower the estimation uncertainty as shown in Fig. 7.

In this figure, simulated data are used to show how regularisation of ML works (the same conclusions are drawn for HOPE regularisation). In Fig. 7a (resp. Fig. 7b), the log-likelihood function (resp. regularised log-likelihood function) is plotted as a function of $H$ and $C_{\mathrm{PHY}}$. The actual $H$ and $C_{\mathrm{PHY}}$ values are $20 \mathrm{~m}$ and $1.7 \mu \mathrm{g} . \mathrm{l}^{-1}$ respectively. For both parameters, the mean of the prior distribution is the actual value and the standard deviation is $10 \%$ of the mean.

One observes that the log-likelihood reached a plateau beyond $16 \mathrm{~m}$ for $C_{\mathrm{PHY}}$ 


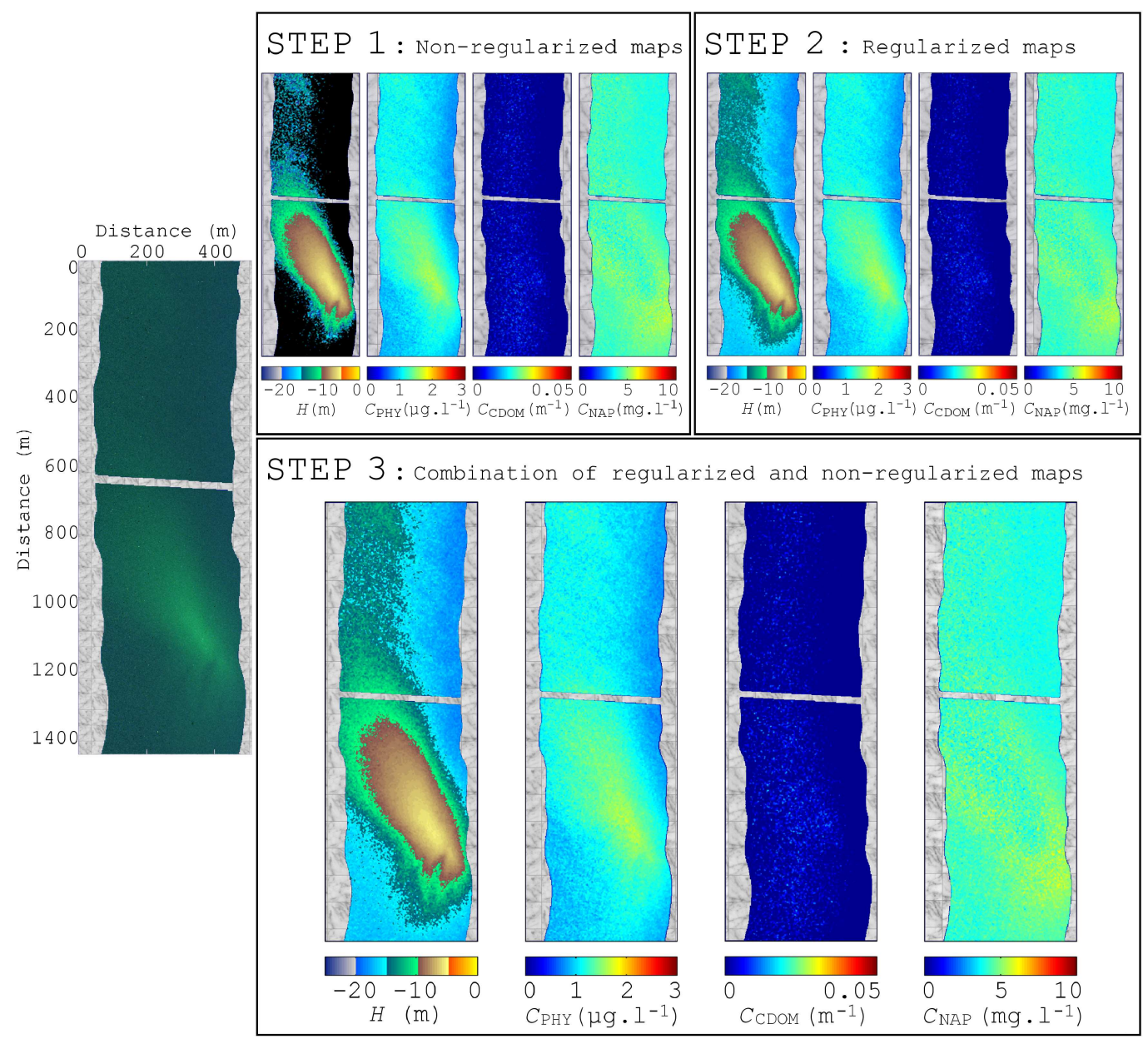

Figure 8. Framework of the proposed methods (either MAP or REG-HOPE) for deep water. Step 1: Maps obtained with the non-regularized method (black areas in the bathymetric map correspond to zones deeper than 25 m); Step 2: Regularization procedure based on maps obtained at step 1; Step 3: Mapping procedure combining regularised and non-regularised maps.

ranging from 1.5 to $2 \mu \mathrm{g} .1^{-1}$. This figure confirms what is shown in Fig.6, i.e., in deep water, every high depth value is almost equally likely, so aberrant values can be obtained using ML estimation. On the other hand, this function was more peaked with respect to $C_{\mathrm{PHY}}$ for depths around $20 \mathrm{~m}$, which shows that this parameter could be still well estimated under these conditions.

As observed in Fig. 7b, after regularisation, the objective function became more peaked with respect to both $H$ and $C_{\mathrm{PHY}}$. As a result, the estimation uncertainty decreased by making aberrant values less likely.

\section{2. $\quad$ Framework of the proposed methods}

Fig. 8 illustrates the framework of the proposed mapping methods using image $\mathrm{D}_{2,+}$. This framework is illustrated using HOPE and REG-HOPE (regularisation with respect to depth), but the procedure is nearly the same for ML and MAP. First, the original method is applied so as to provide non-regularised $H, C_{\mathrm{PHY}}$, $C_{\mathrm{CDOM}}$ and $C_{\mathrm{NAP}}$ maps. In this case, as indicated by the black areas on the estimated bathymetric map, the estimation uncertainty increases for depths higher than around $12 \mathrm{~m}$. As a result, $m_{1}$ and $\sigma_{1}$ can manually be set to $10 \mathrm{~m}$ and $1 \mathrm{~m}$ respectively so that depths higher than $12 \mathrm{~m}$ are penalized since they are in the 


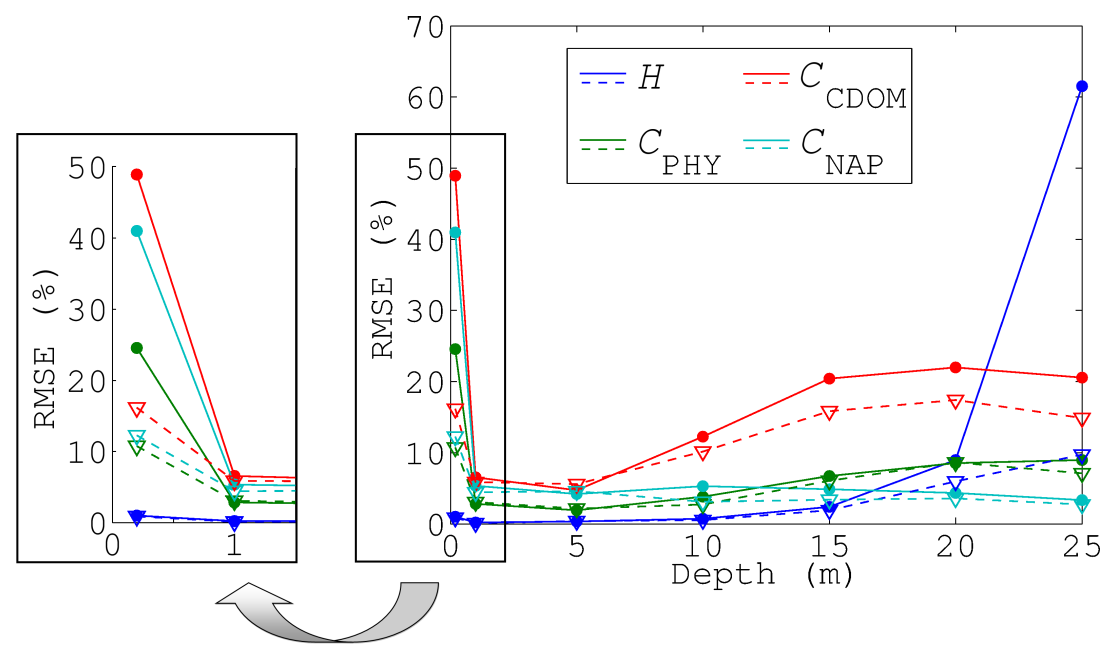

Figure 9. Relative RMSE obtained with ML (solid lines) and MAP (dashed lines) using simulated data. For MAP, the likelihood function was regularised with respect to every parameter, setting $m_{i}$ to the actual value and $\sigma_{i}=30 \% \times m_{i}(N=400$ pixels, $P=50$ runs $)$.

distribution tail. Note that these parameters do not have to be tuned very carefully; for example, choosing $m_{1}=9 \mathrm{~m}$ and $\sigma_{1}=2 \mathrm{~m}$ could work fine as well. Overall, a convenient choice for $m_{1}$ is a value slightly lower to the maximum depth that can be estimated. Additionally, for REG-HOPE, the Lagrange multiplier $w_{1}$ for the whole image is estimated locally in a pixel of known depth. Regularised maps for deep water are therefore computed (Fig. 8, part A).

Second, regularised maps (for deep water) and non-regularised maps (for shallow water) have to be combined according to the mapping procedure described in Section 3.3.4. The values of $H_{\mathrm{INF}}$ and $H_{\mathrm{SUP}}$ are manually chosen close to $m_{1}$ and do not have to be tuned very carefully as well because the non-regularised and regularised maps for a given parameter are quite similar around $m_{1}$. In Fig. 8 (part B), the final estimated maps are computed taking $H_{\mathrm{INF}}=7 \mathrm{~m}$ and $H_{\mathrm{SUP}}=9 \mathrm{~m}$.

\subsection{Estimation results}

\subsubsection{Simulated data}

Regularisation influence on estimation results was first evaluated on simulated hyperspectral data. In Fig. 9, we compare the results obtained using both ML and MAP for depths ranging from 0.20 to $30 \mathrm{~m}$. Subsurface hyperspectral data were simulated according to the procedure described in Section 3.4. For each simulation (50 runs for each depth), $N=400$ pixels were randomly generated to build the statistical sample. Depth and concentrations were then estimated by ML and MAP. For MAP, the prior distribution mean $m_{i}$ of each parameter was set to its actual value, and the standard deviation $\sigma_{i}$ was set to $30 \% \times m_{i}$.

On the one hand, one clearly sees that regularising the objective function with respect to $H$ made the RMSE drop from $60 \%$ to $10 \%$ for deep water (i.e., $25 \mathrm{~m}$ ). On the other hand, it had much fewer effects for lower depths because the initial objective function was more peaked around its maximum. Concerning concentrations, as expected, a noticeable improvement was observed for very shallow water (i.e., $0.20 \mathrm{~m}$ ). For example, the RMSE obtained for $C_{\mathrm{NAP}}$ decreased from $40 \%$ to $13 \%$.

These results confirm that the proposed regularisation is an interesting way to increase estimation accuracy in limiting cases. 
Table 2. Depth estimation results (in $\mathrm{m}$ ) obtained at various known depths (in bold) and for both images $\mathrm{D}_{1}$ and $\mathrm{D}_{2}$.

\begin{tabular}{|c|c|c|c|c|c|c|c|c|c|}
\hline Method & $4.70 \mathrm{~m}$ & $6.70 \mathrm{~m}$ & $7.30 \mathrm{~m}$ & $9.30 \mathrm{~m}$ & $11.80 \mathrm{~m}$ & $14.40 \mathrm{~m}$ & $16.80 \mathrm{~m}$ & $19.40 \mathrm{~m}$ & RMSE (m) \\
\hline ML & 4.44 & 6.40 & 5.73 & 8.70 & 13.58 & 39.43 & 47.50 & 65.12 & 21.22 \\
\hline MAP & 4.44 & 6.40 & 5.73 & 8.70 & 12.39 & 15.99 & 16.91 & 19.55 & 0.85 \\
\hline HOPE & 3.58 & 6.54 & 5.65 & 8.91 & 33.65 & 49.05 & 46.77 & 56.75 & 21.99 \\
\hline $\begin{array}{l}\text { REG- } \\
\text { HOPE }\end{array}$ & 3.58 & 6.54 & 5.65 & 8.91 & 14.25 & 17.23 & 16.07 & 19.72 & 1.53 \\
\hline
\end{tabular}

\subsubsection{Real data}

The estimation performances of regularised methods were also evaluated using the two images presented in Section 2. In this case, both ML and HOPE were only regularised with respect to $H$. Note that, unfortunately, no real data was available to assess the regularisation contribution to improve concentration estimation in very shallow water.

Fig. 10 (resp. Fig. 11) displays the estimated bathymetric maps of image $\mathrm{D}_{1}$ (resp. image $\mathrm{D}_{2}$ ) that were obtained with ML, MAP, HOPE and REG-HOPE. For HOPE and REG-HOPE maps, a $3 \times 3$ pixel median filter was applied afterwards in order to lower the estimation noise obtained for deep water. For these two images and both MAP and REG-HOPE, regularised and non-regularised maps were combined using $H_{\mathrm{INF}}=7 \mathrm{~m}$ and $H_{\mathrm{SUP}}=9 \mathrm{~m}$. Furthermore, regularised maps were obtained using $m_{1}=9 \mathrm{~m}$ and $\sigma_{1}=1 \mathrm{~m}$ for image $D_{1}$, and $m_{1}=10 \mathrm{~m}$ and $\sigma_{1}=1 \mathrm{~m}$ for image $\mathrm{D}_{2}$.

These eight maps have to be compared with the actual bathymetric profile presented in Fig. 2. It is worth recalling that the tide levels were different in the two images, i.e., the actual depth was $2.60 \mathrm{~m}$ higher for image $\mathrm{D}_{2}$.

First, one notes that ML and HOPE accurately estimated depth up to a maximum depth. A shallow zone was found at the center of each image. Depth was then increasing when going to the left side and to the right side. In the spots where the ground truth was measured, the estimated depths were close to the actual depths up to about $12 \mathrm{~m}$ for both methods (see Tab. 2).

Actually, this maximum depth value depends on current water quality (as well as on bottom type, noise level, etc). For both ML and HOPE, these maximum depths were around $13 \mathrm{~m}$ and $14 \mathrm{~m}$ for images $\mathrm{D}_{1}$ and $\mathrm{D}_{2}$ respectively. These limits were different from an image to the other probably because the water quality changed between the two dates (i.e., the water may have become clearer when image $\mathrm{D}_{2}$ was acquired).

In deeper zones, depth was clearly overestimated by both methods, since the estimated values were higher than $25 \mathrm{~m}$. As shown in Fig. 7 using simulated data, for such deep zones, every depth value higher than the actual one is almost equally likely, hence usual estimation methods tend to overestimate this parameter.

On the other hand, in such zones, both MAP and REG-HOPE led to consistent results for depths up to more than $20 \mathrm{~m}$ (for image $\mathrm{D}_{2}$ ). For both images $\mathrm{D}_{1}$ and $\mathrm{D}_{2}$, the estimated depth gradients were in the appropriate directions, especially for deeper areas. For example, the depth gradient direction was oblique in the lower left part and the upper right part, while it was horizontal in the lower right part. 


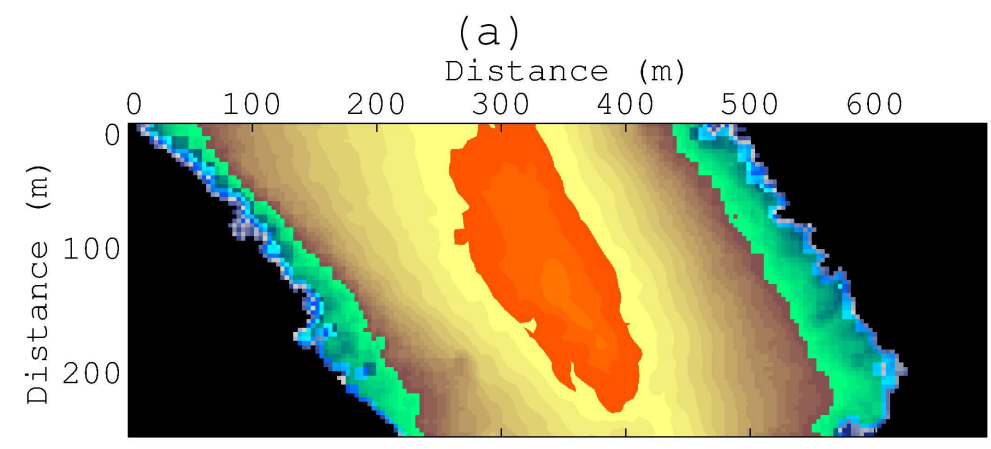

(b)

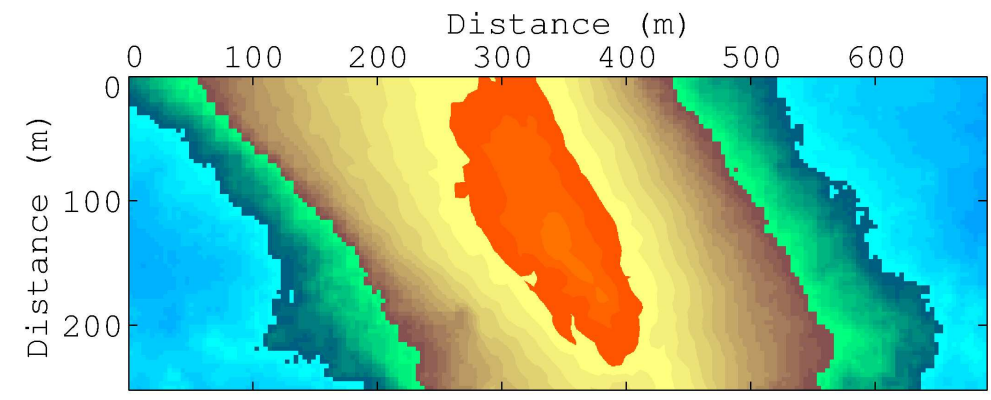

( C)

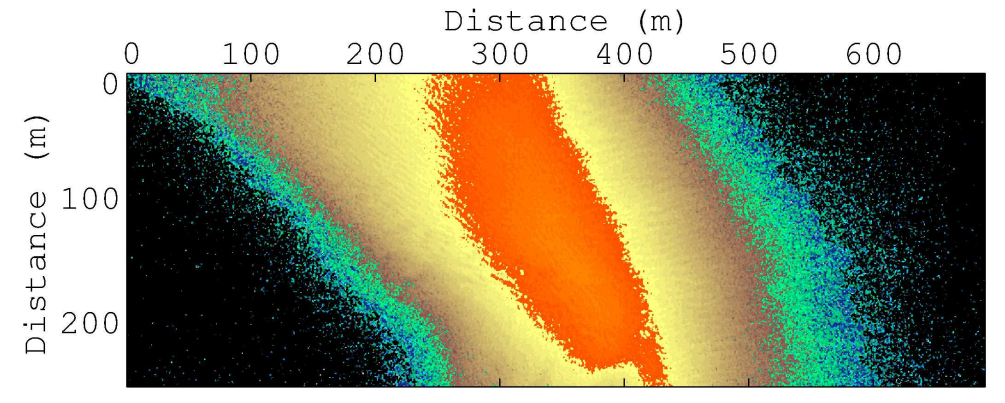

(d)

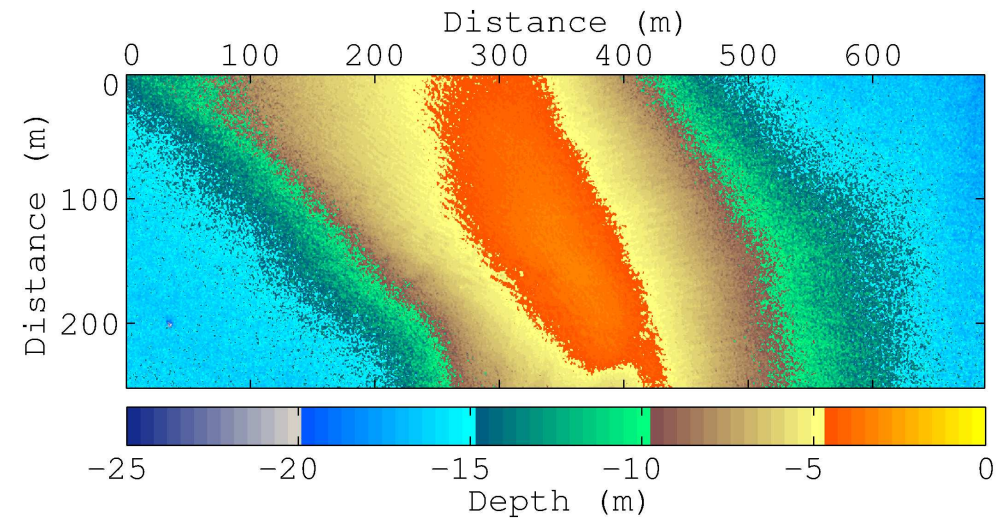

Figure 10. Estimated bathymetric maps of image $\mathrm{D}_{1}$ obtained with (a) ML, (b) MAP, (c) HOPE and (d) REG-HOPE. Black areas correspond to zones where estimated values are higher than $25 \mathrm{~m}$.

Moreover, as displayed in Tab. 2, MAP and REG-HOPE led to quite lower RMSE values $(0.85 \mathrm{~m}$ and $1.53 \mathrm{~m}$ resp.) where the ground truth was measured (from depths ranging from 4.70 to $19.40 \mathrm{~m}$ ), thereby confirming the strong agreement observed between the actual and estimated bathymetric profiles. These results show that, compared with non-regularised methods, the regularisations performed using the above $H_{\mathrm{INF}}, H_{\mathrm{SUP}}, m_{1}$ and $\sigma_{1}$ parameters allowed for improving depth estimation 


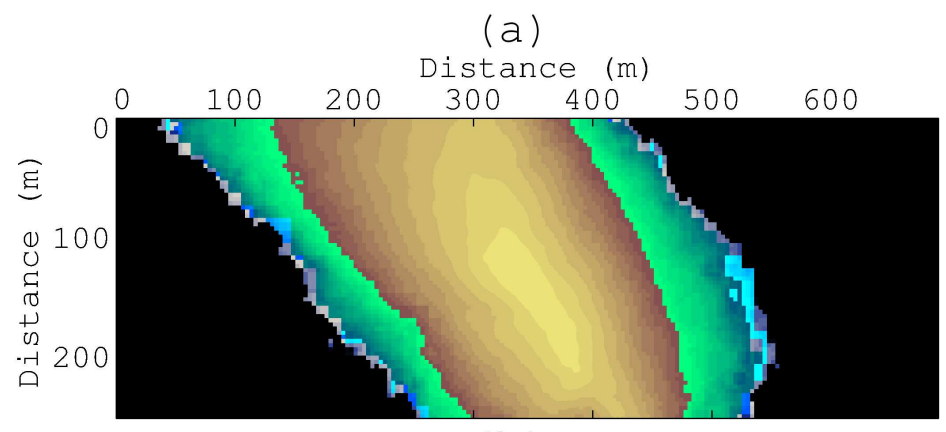

(b)

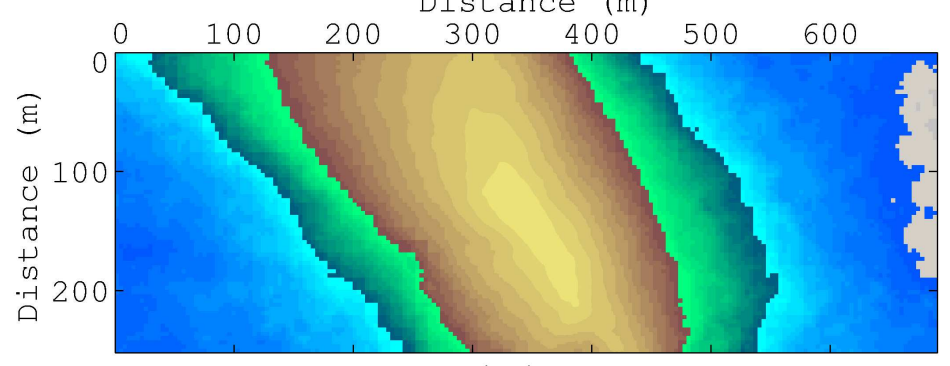

( C )

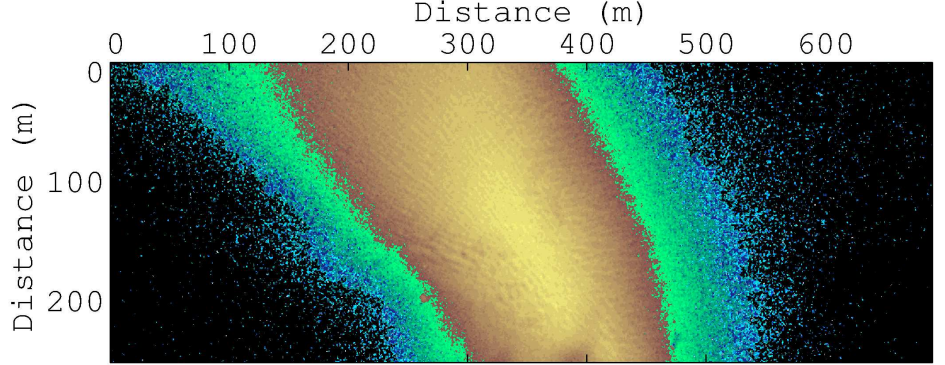

(d)

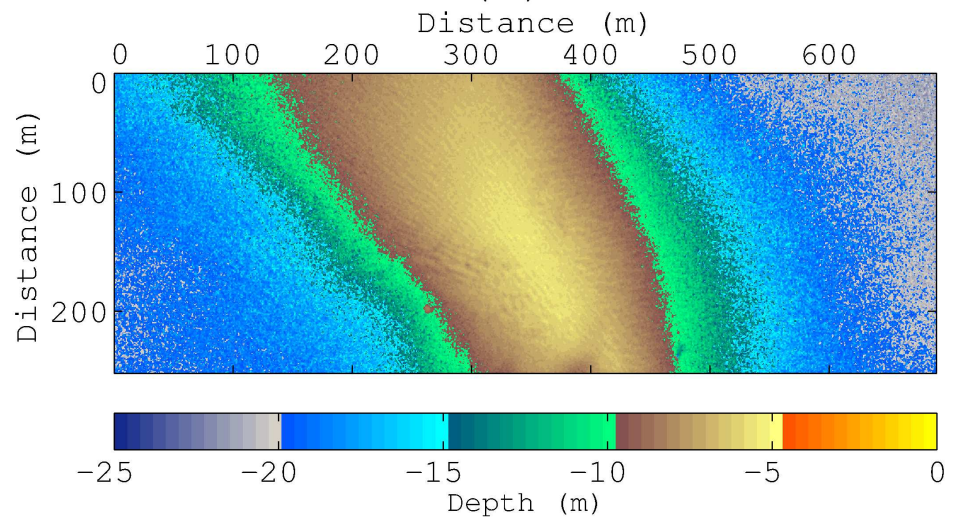

Figure 11. Estimated bathymetric maps of image $\mathrm{D}_{2}$ obtained with (a) ML, (b) MAP, (c) HOPE and (d) REG-HOPE. Black areas correspond to zones where estimated values are higher than $25 \mathrm{~m}$.

in deep water.

Lastly, regularising the objective functions with respect to depth does not affect the concentration estimation. Tab. 3 shows that the errors obtained by the original methods and their regularised counterpart were nearly the same, since they all led to a RMSE of $0.8 \mu \mathrm{g} . \mathrm{l}^{-1}$ for $C_{\mathrm{PHY}}$. Therefore, these results prove that in deep water, regularising the objective functions can clearly improve depth estimation performances while not affecting the concentration estimation. 
Table 3. Concentration estimation results obtained at various known depths (in bold) and for image $\mathrm{D}_{1}\left(C_{\mathrm{PHY}}\right.$ in $\mu \mathrm{g} . \mathrm{l}^{-1}, C_{\mathrm{NAP}}$ in $\left.\mathrm{mg} . \mathrm{l}^{-1}\right)$. RMSE values are only provided for $C_{\mathrm{PHY}}$ estimation.

\begin{tabular}{ccccccc}
\hline Method & Variable & $\mathbf{4 . 7 0} \mathbf{~}$ & $\mathbf{6 . 7 0} \mathbf{~ m}$ & $\mathbf{1 1 . 8 0} \mathbf{~ m}$ & $\mathbf{1 6 . 8 0} \mathbf{~ m}$ & RMSE $\left(\mu \mathrm{gg. \mathbf {l } ^ { - 1 }}\right)$ \\
\hline \multirow{2}{*}{ ML } & $\boldsymbol{C}_{\text {PHY }}$ & 2.6 & 2.0 & 1.8 & 1.5 & 0.8 \\
& $\boldsymbol{C}_{\text {NAP }}$ & 1.6 & 3.7 & 5.4 & 5.6 & $\times$ \\
\hline \multirow{2}{*}{ MAP } & $\boldsymbol{C}_{\text {PHY }}$ & 2.6 & 2.0 & 1.8 & 1.5 & 0.8 \\
& $C_{\text {NAP }}$ & 1.6 & 3.7 & 5.3 & 5.5 & $\times$ \\
\hline \multirow{2}{*}{ HOPE } & $C_{\text {PHY }}$ & 2.3 & 2.0 & 1.5 & 1.3 & 0.8 \\
& $C_{\text {NAP }}$ & 4.0 & 6.1 & 6.1 & 5.5 & $\times$ \\
\hline \multirow{2}{*}{ REG- } & $C_{\text {PHY }}$ & 2.3 & 2.0 & 1.3 & 1.1 & 0.8 \\
HOPE & $C_{\text {NAP }}$ & 4.0 & 6.1 & 5.9 & 5.4 & $\times$ \\
\hline
\end{tabular}

\section{Conclusions and perspectives}

In this study, we show that regularising the objective functions of two estimation methods (ML and HOPE) can greatly improve the retrieval process for some particular depth ranges. Indeed, concentrations and depth cannot be accurately estimated in very shallow water or in deep water respectively, because they do not affect much the subsurface reflectance. Adding some appropriate regularisation terms enhances the influence of these parameters. In particular, when tested on real hyperspectral remote-sensing images, such methods regularised with respect to depth led to accurate bathymetric maps up to $20 \mathrm{~m}$ for the two considered water qualities, while non-regularised methods were accurate up to $12 \mathrm{~m}$.

On the one hand, methods regularised with respect to depth can easily be implemented to improve depth estimation in deep water, because there is no need for additional data, the regularisation terms being extracted from the originally estimated bathymetric maps. On the other hand, using regularisation to improve water quality retrieval for very shallow water theoretically requires a statistically sound database that is inherent to the considered area. Even if some of these databases already exist (e.g., the one of Ifremer (2011) for the French coast), they are usually unavailable in the required fullness, which may hinder the use of regularisation in such a case. However, it is worth noting that, if no database is available, rough approximations of concentration distributions can simply be used to avoid aberrant estimated values and to improve the overall estimation. Furthermore, the need for such databases may serve as a guideline for some dedicated projects aiming at building up such site-specific databases.

In this study, regularised methods have been evaluated in homogeneous sandy habitats because, in its current version, ML (and therefore MAP) assumes that the water quality and bottom type are homogeneous within a local neighbourhood (i.e., the statistical sample). To deal with more complex bottom covers or lower spatial resolutions, the generalization of ML and MAP to heterogeneous bottoms is currently investigated and involves a modified likelihood function and an unmixing technique to provide a different estimate of bottom spectrum in each pixel (Guillaume, Michels, and Jay 2015).

Note that the proposed regularisation approach can naturally be extended either to multispectral data (similarly to non-regularised methods) and to other similar estimation method in the same way. It can also be used to better estimate other model parameters such as bottom parametrisation. Lastly, it would be interesting 
to assess regularised methods for other water quality conditions and to consider the parameter inter-dependency within prior distributions because, in particular, the concentrations of different parameters may vary together.

\section{Acknowledgements}

This work was supported by the Office for Advanced Research and Innovation (DGA/MRIS). We are also grateful to Actimar, which carried out the field measurement campaign within the exploratory research and innovation project named "HypLitt" and funded by the French Defense Agency (DGA). ActiMar is a company specialized in operational oceanography and high resolution remote sensing, based in Brest, France (www.actimar.fr).

\section{References}

AFNOR. 2012. "NF EN 872 - Dosage des matieres en suspension Méthode par filtration sur filtre en fibres de verre." In Qualité de l'eau, edited by AFNOR Editions.

AFNOR. December 1999. Qualit de l'eau, Dosage de la chlorophylle a et d'un indice phopigments - Mthode par spectromtrie d'absorption molculaire.

Ahn, Y.H., A. Bricaud, and A. Morel. 1992. "Light backscattering efficiency and related properties of some phytoplankters." Deep Sea Research 39: 1835-1855.

Baret, Frederic, and Samuel Buis. 2008. "Estimating canopy characteristics from remote sensing observations: Review of methods and associated problems." In Advances in land remote Sensing, 173-201. Springer.

Brando, V.E., J.M. Anstee, M. Wettle, A.G. Dekker, S.R. Phinn, and C. Roelfsema. 2009. "A physics based retrieval and quality assessment of bathymetry from suboptimal hyperspectral data." Remote Sensing of Environment 113: 755-770.

Buiteveld, Hendrik, JHM Hakvoort, and M Donze. 1994. "Optical properties of pure water." In Ocean Optics XII, 174-183. International Society for Optics and Photonics.

Cannizzaro, J.P., and K.L. Carder. 2006. "Estimating chlorophyll a concentrations from remote-sensing reflectance in optically shallow waters." Remote Sensing of Environment 101: $13-24$.

Carder, KL, FR Chen, JP Cannizzaro, JW Campbell, and BG Mitchell. 2004. "Performance of the MODIS semi-analytical ocean color algorithm for chlorophyll-a." Advances in Space Research 33 (7): 1152-1159.

Clark, Roger N, Gregg A Swayze, K Eric Livo, Raymond F Kokaly, Trude VV King, J Brad Dalton, J Sam Vance, Barnaby W Rockwell, Todd Hoefen, and Robert R McDougal. 2002. "Surface reflectance calibration of terrestrial imaging spectroscopy data: a tutorial using AVIRIS." In Proceedings of the 10th Airborne Earth Science Workshop, 02-1. Jet Propulsion laboratory Pasadena, CA.

Defoin-Platel, Michael, and Malik Chami. 2007. "How ambiguous is the inverse problem of ocean color in coastal waters?." Journal of Geophysical Research: Oceans (1978-2012) 112 (C3).

Dekker, Arnold G, Stuart R Phinn, Janet Anstee, Paul Bissett, Vittorio E Brando, Brandon Casey, Peter Fearns, et al. 2011. "Intercomparison of shallow water bathymetry, hydro-optics, and benthos mapping techniques in Australian and Caribbean coastal environments." Limnology and Oceanography: Methods 9: 396-425.

Doxaran, D., J.M. Froidefond, Castaing P., and Babin M. 2009. "Dynamics of the turbidity maximum zone in a macrotidal estuary (the Gironde, France): observations from field and MODIS satellite data." Estuarine, Coastal and Shelf Science 81: 312-332.

Ferreira, Amabile, Carlos A.E. Garcia, Ana I. Dogliotti, and Virginia M.T. Garcia. 2013. "Bio-optical characteristics of the Patagonia Shelf break waters: Implications for ocean color algorithms." Remote Sensing of Environment 136 (0): 416 - 432. 
Garcia, Rodrigo A., Peter R.C.S. Fearns, and Lachlan I.W. McKinna. 2014. "Detecting trend and seasonal changes in bathymetry derived from HICO imagery: a case study of Shark Bay, Western Australia." Remote Sensing of Environment 147 (0): 186 - 205.

Giardino, Claudia, Gabriele Candiani, Mariano Bresciani, Zhongping Lee, Stefano Gagliano, and Monica Pepe. 2012. "BOMBER: A tool for estimating water quality and bottom properties from remote sensing images." Computers and Geosciences 45 (0): 313 -318 .

Goodman, J., Z. Lee, and S.L. Ustin. 2008. "Influence of atmospheric and sea-surface corrections on retrieval of bottom depth and reflectance using a semi-analytical model: a case study in Kaneohe Bay, Hawaii." Applied Optics 47 (28): F1-F11.

Guillaume, M., Y. Michels, and S. Jay. 2015. "Joint estimation of water column parameters and seabed reflectance combining maximum likelihood and unmixing algorithm." Proc. of 7th Workshop on Hyperspectral Image and Signal Processing: Evolution in Remote Sensing (WHISPERS).

Hedley, J., C. Roelfsema, and S.R. Phinn. 2009. "Efficient radiative transfer model inversion for remote sensing applications." Remote Sensing of Environment 113: 2527-2532.

Huck, Alexis, Mireille Guillaume, and Jacques Blanc-Talon. 2010. "Minimum dispersion constrained nonnegative matrix factorization to unmix hyperspectral data." Geoscience and Remote Sensing, IEEE Transactions on 48 (6): 2590-2602.

Ifremer. 2011. "Site IFREMER consacré á l'environnement littoral." http://www . ifremer.fr/envlit/.

Jay, S. 2012. "Estimation et détection en imagerie hyperspectrale, application aux environnements cotiers." Ph.D. thesis. Ecole Centrale Marseille.

Jay, S., and M. Guillaume. 2011. "Estimation of water column parameters with a maximum likelihood approach." Proc. of 3rd Workshop on Hyperspectral Image and Signal Processing: Evolution in Remote Sensing (WHISPERS) 1-4.

Jay, S., and M. Guillaume. 2014. "A novel maximum likelihood based method for mapping depth and water quality from hyperspectral remote-sensing data." Remote Sensing of Environment 147: 121-132.

Jay, S., M. Guillaume, and J. Blanc-Talon. 2012. "Underwater target detection with hyperspectral data: solutions for both known and unknown water quality." IEEE Journal of Selected Topics in Applied Earth Observations and Remote Sensing 5 (4): 1213-1221.

Klonowski, W.M., P.R.C.S. Fearns, and M.J. Lynch. 2007. "Retrieving key benthic cover types and bathymetry from hyperspectral imagery." Journal of Applied Remote Sensing 1.

Kutser, T. 2004. "Quantitative detection of chlorophyll in cyanobacterial blooms by satellite remote sensing." Limnology and Oceanography 49: 2179-2189.

Lee, Z.P. 1994. "Visible-infrared remote-sensing model and applications for ocean waters." Ph.D. thesis. University of South Florida.

Lee, Z.P., K.L. Carder, C.D. Mobely, R.G. Steward, and J.S. Patch. 1999. "Hyperspectral remote sensing for shallow waters. II. Deriving bottom depths and water properties by optimization." Applied Optics 38: 3831-3843.

Lee, Zhongping, Kendall L. Carder, Curtis D. Mobley, Robert G. Steward, and Jennifer S. Patch. 1998. "Hyperspectral Remote Sensing for Shallow Waters. I. A Semianalytical Model." Applied Optics 37 (27): 6329-6338.

Loisel, Hubert, Antoine Mangin, Vincent Vantrepotte, David Dessailly, Dat Ngoc Dinh, Philippe Garnesson, Sylvain Ouillon, Jean-Pierre Lefebvre, Xavier Mériaux, and Thu Minh Phan. 2014. "Variability of suspended particulate matter concentration in coastal waters under the Mekong's influence from ocean color (MERIS) remote sensing over the last decade." Remote Sensing of Environment 150 (0): 218 - 230.

Louchard, E.M., R.P. Reid, F.C Stephens, C.O. Davis, R.A. Leathers, and T.V. Downes. 2003. "Optical remote sensing of benthic habitats and bathymetry in coastal environments at Lee Stocking Island, Bahamas: A comparative spectral classification approach." Limnology and Oceanography 48: 511-521.

Lyzenga, D.R. 1978. "Passive remote sensing techniques for mapping water depth and bottom features." Applied Optics 17: 379-383. 
Maritorena, Stephane, A. Morel, and B. Gentili. 1994. "Diffuse reflectance of oceanic shallow waters - influence of water depth and bottom albedo." Limnology and Oceanography 39: 1689-1703.

Matthews, M.W., S. Bernard, and K. Winter. 2010. "Remote sensing of cyanobacteriadominant algal blooms and water quality parameters in Zeekoevlei, a small hypertrophic lake, using MERIS." Remote sensing of environment 114: 2070-2087.

Minghelli-Roman, A., L. Mathieu-Blanc, L. Loubersac, and F. Cauneau. 2007. "Bathymetric estimation using MERIS images in coastal sea waters." IEEE Geoscience and Remote Sensing Letters 4: 274-277.

Mobley, C.D., L.K. Sundman, C.O. Davis, J.H. Bowles, T.V. Downes, R.A. Leathers, M.J. Montes, et al. 2005. "Interpretation of hyperspectral remote-sensing imagery by spectrum matching and look-up tables.." Applied Optics 44: 3576-3592.

Morel, A. 1974. "Optical properties of pure water and pure sea water." Optical Aspects of Oceanography 1-24.

O’Reilly, J.E., S. Maritorena, B.G. Mitchell, D.A. Siegel, K.L. Carder, S.A. Garver, M. Kahru, and C. McClain. 1998. "Ocean color chlorophyll algorithms for SeaWiFS." Journal of Geophysical Research 103: 24937-24953.

Philpot, W.D. 1989. "Bathymetric mapping with passive multispectral imagery." Applied Optics 28: 1569-1578.

Pope, R.M., and E.S. Fry. 1997. "Absorption spectrum (380-700nm) of pure water. ii. integrating cavity measurements." Applied Optics 36: 8710-8723.

Richardson, L.L., and E.F. LeDrew. 2006. Remote Sensing of Aquatic Coastal Ecosystem Processes : Science and Management Applications. Netherlands: Springer.

Richter, R. 2012. Atmospheric / topographic correction for airborne imagery: ATCOR-4 User Guide. Wessling, Germany: DLR IB 565-02/11.

Savitsky, A., and M.E.J. Golay. 1964. "Smoothing and Differentiation of Data by Simplified Least Squares Procedures." Analytical Chemistry 8 (36): 16271639.

Smet, S., G. Sicot, and M. Lennon. 2010. Evaluation des capacités de le télédétection hyperspectrale et développement de méthodes innovantes de traitement d'images pour des applications Défense en zone littorale (HypLitt). Tech. rep.., contrat de recherche DGA 2010340014.

Smith, R.C., and K.S. Baker. 1981. "Optical properties of the clearest natural waters (200-800 nm)." Applied Optics 20: 177-184.

Sydor, M., R.W. Gould, R.A. Arnone, V.I. Haltrin, and W. Goode. 2004. "Uniqueness in remote sensing of the inherent optical properties of ocean water." Applied optics 43: 2156-2162.

Tian, H., C. Cao, M. Xu, Z. Zhu, D. Liu, X. Wang, and S. Cui. 2014. "Estimation of chlorophyll- $a$ concentration in coastal waters with HJ-1A HSI data using a three-band bio-optical model and validation." International Journal of Remote Sensing 35 (16): 5984-6003.

Volpe, V., S. Silvestri, and M. Marani. 2011. "Remote sensing retrieval of suspended sediment concentration in shallow waters." Remote Sensing of Environment 115: 44-54.

Xiu, P., Y. Liu, G. Li, Q. Xu, H. Zong, Z. Rong, X. Yin, and F. Chai. 2009. "Deriving depths of deep chlorophyll maximum and water inherent optical properties: a regional model." Continental Shelf Research 29 (19): 2270-2279.

Zhu, Weining, Qian Yu, Yong Q. Tian, Brian L. Becker, Tao Zheng, and Hunter J. Carrick. 2014. "An assessment of remote sensing algorithms for colored dissolved organic matter in complex freshwater environments." Remote Sensing of Environment 140 (0): 766 778 . 